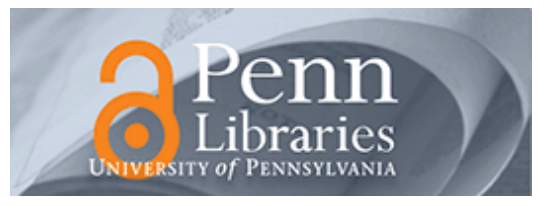

University of Pennsylvania

ScholarlyCommons

Finance Papers

Wharton Faculty Research

2013

\title{
CEO Compensation and Corporate Risk: Evidence From a Natural Experiment
}

Todd A. Gormley

University of Pennsylvania

David A. Matsa

Todd Milbourne

Follow this and additional works at: https://repository.upenn.edu/fnce_papers

Part of the Corporate Finance Commons, and the Finance and Financial Management Commons

\section{Recommended Citation}

Gormley, T. A., Matsa, D. A., \& Milbourne, T. (2013). CEO Compensation and Corporate Risk: Evidence From a Natural Experiment. Journal of Accounting and Economics, 56 (2-3), 79-101. http://dx.doi.org/10.1016/ j.jacceco.2013.08.001

This paper is posted at ScholarlyCommons. https://repository.upenn.edu/fnce_papers/398

For more information, please contact repository@pobox.upenn.edu. 


\title{
CEO Compensation and Corporate Risk: Evidence From a Natural Experiment
}

\author{
Abstract \\ This paper examines the two-way relationship between managerial compensation and corporate risk by \\ exploiting an unanticipated change in firms' business risks. The natural experiment provides an \\ opportunity to examine two classic questions related to incentives and risk-how boards adjust incentives \\ in response to firms' risk and how these incentives affect managers' risk-taking. We find that, after left-tail \\ risk increases, boards reduce managers' exposure to stock price movements and that less convexity from \\ options-based pay leads to greater risk-reducing activities. Specifically, managers with less convex \\ payoffs tend to cut leverage and R\&D, stockpile cash, and engage in more diversifying acquisitions.

\section{Disciplines} \\ Corporate Finance | Finance and Financial Management
}




\title{
CEO compensation and corporate risk: Evidence from a natural experiment ${ }^{\text {tै }}$
}

\author{
Todd A. Gormley ${ }^{\mathrm{a}}$, David A. Matsa ${ }^{\mathrm{b}, *}$, Todd Milbourn ${ }^{\mathrm{c}}$ \\ ${ }^{a}$ The Wharton School, University of Pennsylvania, USA \\ ${ }^{\mathrm{b}}$ Kellogg School of Management, Northwestern University, USA \\ ${ }^{c}$ Olin Business School, Washington University in St. Louis, USA
}

August 19, 2013

\begin{abstract}
This paper examines the two-way relationship between managerial compensation and corporate risk by exploiting an unanticipated change in firms' business risks. The natural experiment provides an opportunity to examine two classic questions related to incentives and risk-how boards adjust incentives in response to firms' risk and how these incentives affect managers' risk-taking. We find that, after left-tail risk increases, boards reduce managers' exposure to stock price movements and that less convexity from options-based pay leads to greater risk-reducing activities. Specifically, managers with less convex payoffs tend to cut leverage and $R \& D$, stockpile cash, and engage in more diversifying acquisitions.
\end{abstract}

JEL classifications: J33, G32, G34, K13

Keywords: Legal liability, Regulatory risk, Tail risk, Stock options, Compensation, Managerial incentives

\footnotetext{
* We are grateful to John Core (the Editor) and an anonymous referee for their help in revising the paper. We also thank Rajesh Aggarwal, Yakov Amihud, Christopher Armstrong, Michal Barzuza, Jennifer Carpenter, Ingolf Dittmann, Alex Edmans, Charles Hadlock, Andrew Karolyi, Michael Lemmon, Paul Oyer, Nagpurnanand Prabhala, Nicholas Souleles, Anjan Thakor, and the seminar participants at Columbia University, Cornell University, Erasmus University, London School of Economics, Michigan State University, New York University, University of Illinois, University of Maryland, University of Oklahoma, University of Pennsylvania, the JAE Annual Conference, and the NYU/Penn Conference on Law and Finance for helpful comments. We are grateful to Randy O. Young and William K. Sieber at the Center for Disease Control, David Yermack, and James S. Linck for providing data, and to Dashan Huang for research assistance. Gormley also thanks the Rodney L. White Center for Financial Research Brandywine Global Investment Management Research Fellowship and the Cynthia and Bennett Golub Endowed Faculty Scholar Award for financial support. All remaining errors are our own.

${ }^{*}$ Corresponding author. Tel.: +1 8474918337.

E-mail address: dmatsa@kellogg.northwestern.edu (D.A. Matsa).
} 


\section{Highlights}

"CEO Compensation and Corporate Risk:

Evidence from a Natural Experiment"

- Convex managerial payoffs and firm risk are known to be correlated, but the direction of causality remains unclear.

- We exploit a change in risk to show how boards adjust incentives and how these incentives affect managers' risk-taking.

- We find that firms reduce managers' exposure to stock price movements after left-tail risk increases.

- Because the change in risk is unanticipated, we can also identify compensation's effect on risktaking in the new environment.

- Our results show that convexity from options can encourage risk-taking in corporate investment and financing decisions. 


\section{Introduction}

Option-based compensation for corporate executives has grown significantly over the past 30 years. It is commonly believed that stock options provide managers with incentives to take risks, but the evidence remains unclear. Even less is known about how boards of directors design and adjust managers' incentives in light of firms' risk environments. The lack of definitive findings may seem surprising given that the issue has been studied extensively. However, theoretical predictions are varied and overcoming identification concerns remains challenging. In this paper, we take a new approach to these classic issues in an attempt to augment our understanding of the relationship between risk and incentives.

Providing empirical evidence is important because theory's prediction of how options affect risktaking incentives is ambiguous. On the one hand, options' convex payoffs create an incentive to take risk because managers share in the gains but not all of the losses. This intuition appears in Jensen and Meckling (1976), Myers (1977), Smith and Stulz (1985), and Smith and Watts (1992). ${ }^{1}$ On the other hand, Lambert et al. (1991) show that, because options contain a leveraged position in the firm's equity, options also have the potential to magnify a risk-averse manager's exposure to the firm's risk and thus reduce the manager's appetite for risk taking. ${ }^{2}$

Despite this theoretical ambiguity, there is a wealth of empirical evidence highlighting a positive correlation between the use of options in pay and various measures of risk, such as stock-return volatility. Work of this nature dates back to Agrawal and Mandelker (1987), if not earlier, and extends to Tchistyi et al. (2011). ${ }^{3}$ For example, Guay (1999) shows that it is specifically the convexity of stock options that determines the sensitivity of CEO wealth to equity risk. He finds that firms' stock-return volatility is positively associated with the convexity of the CEO's full compensation package (including previously granted stock and options), which has come to be known as "vega".

\footnotetext{
${ }^{1}$ See also Haugen and Senbet (1981), Bizjak et al. (1993), Gaver and Gaver (1993), and Guay (1999).

${ }^{2}$ Option compensation may also increase or decrease the firm's risk as a by-product of increasing managerial effort (Kadan and Swinkels, 2008). See also Carpenter (2000) and Ross (2004).

${ }^{3}$ Papers documenting a positive association between options and firm risk include DeFusco et al. (1990), Saunders et al. (1990), Mehran (1992, 1995), May (1995), Tufano (1996), Berger et al. (1997), Denis et al. (1997), Esty (1997a, 1997b), Jolls (1998), Schrand and Unal (1998), Aggarwal and Samwick (1999), Guay (1999), and Knopf et al. (2002).
} 
Although this evidence suggests that risk-taking and vega are linked, identifying the causal effect of option-based incentives on corporate risk-taking is difficult given the obvious endogeneity of the relationship between options and risk. Because managers' compensation is arguably designed in anticipation of a particular risk environment, the possibility of reverse causality is hard to exclude. Similar concerns about endogeneity plague the empirical literature on ownership concentration and firm value (Demsetz and Lehn, 1985; Himmelberg et al., 1999; Palia, 2001).

There have been several attempts to solve this identification challenge. A number of papers approach this question by estimating a system of simultaneous equations (see Coles et al., 2006; Rajgopal and Shevlin, 2002; Rogers 2002). Although this approach makes progress by modeling the effects of vega on decisions and vice versa, a fundamental concern remains in that the estimations in these papers require arbitrary exclusion restrictions. ${ }^{4}$ A similar concern applies to Armstrong and Vashishtha (2012) and Shue and Townsend (2013), who attempt to resolve the endogeneity problem using instrumental variables. ${ }^{\mathbf{5}}$ Other recent work attempts to overcome the challenge by analyzing firms' risk-taking following new accounting rules that reduced options pay (Chava and Purnanandam, 2010; Hayes et al., 2012). These new accounting rules, however, were known and debated for years in advance, undermining their effectiveness as a natural experiment; ${ }^{6}$ further, because the rule change affected all firms at the same time, these analyses lack a compelling counterfactual. In sum, although the estimation strategies in this literature have grown more sophisticated and certainly made progress, important identification concerns remain.

We take a step forward in addressing the identification challenge by exploiting changes in firms' business environments that increase left-tail risk (also known as material risk) that can truly be classified

\footnotetext{
${ }^{4}$ Coles et al. (2006) assume that the riskiness of the firm's business environment does not affect project choice; Rajgopal and Shevlin (2002) assume that cash balances and firm size are unrelated to firms' risk choices; and Rogers (2002) assumes that cash balances and stock variance are unrelated to firms' hedging motives.

${ }^{5}$ Armstrong and Vashishtha (2012) assume that cash balances, marginal tax rates, past stock returns, and past profitability are unrelated to the proportion of firms' overall risk that is systematic. Shue and Townsend (2013) exploit the multi-year nature of firms' fixed value and fixed number option grants to create instruments for when managers' holdings of options increase. This approach requires the assumption that boards set the type and/or duration of these plans exogenously and without consideration for the consequences of these choices.

${ }^{6}$ For example, Aboody et al. (2004) highlight that over one hundred firms voluntarily expensed stock options as early as 2002 in anticipation of the 2005 adoption of FAS 123R, which was studied by Chava and Purnanandam (2010) and Hayes et al. (2012).
} 
as exogenous and unanticipated. Left-tail risks are prevalent in practice and can take the form of technological irrelevance, adverse regulatory changes, asset expropriation, and so on. The specific tail risk we study is the risk of large legal liabilities and costly regulation. This setting provides an opening to examine how managers respond to an increase in business risk as a function of their pre-existing equitybased incentives. The unanticipated change in risk allows us to exclude the possibility of reverse causality between these pre-determined incentives and managers' subsequent risk-related choices.

Our empirical analysis centers on a jump in tail risk that is created when a chemical to which a firm's workers have already been exposed is newly identified as a carcinogen. Discovery of a chemical's carcinogenicity increases the likelihood that a firm will need to spend large sums on legal fees, damage payments, and insurance premiums in the future. By increasing the probability that cash flows will be diverted to cover liability costs, this liability risk directly reduces the expected proceeds from new investments that use the chemical as an input to production. The discovery can also create a debt overhang problem, as described in Myers (1977). To the extent that future lawsuits or adverse regulatory changes might consume the cash returned from a new investment, even if it does not use the carcinogen directly, shareholders will be less willing to contribute the capital needed to fund the investment. Even if no additional capital needs to be raised, shareholders might prefer for the firm to pay out existing cash holdings, by increasing dividends or share repurchases, rather than to fund the new investment.

Gormley and Matsa (2011) confirm that such workplace exposures to carcinogens can increase a firm's downside risk and reduce shareholders' willingness to fund new investments. Using data on workplace exposures to known carcinogens, historical damage awards, and historical cash flows, Gormley and Matsa find that a typical potential legal liability faced by firms appears to be around 5\% of assets and that such a shock would increase the median probability of distress among exposed firms by 30 -fold. This underestimates the risk, as it does not account for the possibility of adverse future regulatory changes. ${ }^{7}$ Consistent with a decline in shareholders' desired investment, Gormley and Matsa find that shareholders prefer for managers to pay out more cash after the tail risk increases.

\footnotetext{
${ }^{7}$ An analysis of firms' stock volatility in our sample (discussed later) also suggests that these exposures are salient; the variance of stock returns for firms with an exposure increases by $60 \%$ after risk increases.
} 
Given the drop in desired investment, boards have reason to reduce managers' exposure to their firms' risk. With fewer risky projects that shareholders are willing to fund, the boards no longer need to provide risk-averse managers with as much pay convexity (vega) or sensitivity to firm value (known as "delta") as incentives to undertake risky investments (e.g., Hirshleifer and Suh, 1992; Smith and Watts, 1992). Other factors, discussed in Section 2.1, might also cause boards to decrease stock-based incentives and lead managers to alter their financial exposure to the firm (e.g., by exercising options). While new compensation awards can adjust quickly, managers' overall sensitivities to stock price movements and stock volatility are likely slower to adjust. Vesting schedules restrict the managers' ability to reduce their personal holdings, and it can be costly for firms to modify securities that have already been awarded.

Consistent with the tail risk reducing shareholders' desire to fund new investments, we find that boards respond by immediately adjusting compensation flows so as to reduce managers' exposure to their firms' risks. Boards reduce the sensitivities of CEOs' pay to changes in firm value (delta) and to changes in the firm's risk (vega) in the years immediately after the firm is exposed. In this way, the firms appear to actively manage grants of new equity incentives, consistent with Core and Guay (1999). We also find that managers seek to reduce their future exposure by exercising a greater number of stock options just after the carcinogen is discovered. These results underscore concerns about reverse causality in prior studies of CEO incentives' effect on corporate risk-taking.

In contrast to our findings for compensation flows, however, we find that the sensitivity of the manager's overall compensation portfolio to firm risk is harder to modify quickly. We find that it takes three to five years before the vega and delta of the entire compensation portfolio are significantly reduced. That is, although boards react quickly to adjust new incentives in light of the increased risk, these changes take time to shift the sensitivity of incumbent CEOs' total firm-related wealth to firm risk. The opposite is true for new CEOs, for whom the board gets a fresh start in fashioning incentives. Indeed, we find that new CEOs have significantly lower portfolio vegas than do the CEOs they replace at the exposed firms and lower portfolio vegas than do other newly appointed CEOs at unexposed firms.

To identify an effect of convexity on risk-taking behavior, we make use of a previously 
unexplored effect of convexity on risk-taking incentives. Using a theoretical example in the framework of Lambert et al. (1991), we show that the convexity of CEOs' payoffs affects both the desired level of risktaking and how sensitive CEOs are to deviations from this level. Unlike the prior literature, we focus on the latter effect of convexity. After an unanticipated increase in risk pushes a risk-averse manager above his or her desired level of risk taking, the manager can benefit by reducing risk. However, when the manager has a convex payoff, he or she gains less by reducing risk because the reduction lowers the expected value of the convex payoff. Higher vega thereby provides the manager with the incentive to reduce risk less aggressively.

The unanticipated increase in left-tail risk thus affords us a unique opportunity to identify a causal effect of these incentives on managerial risk-taking. As illustrated by our theoretical framework, the level of convexity immediately after risk increases affects risk-taking incentives in the new environment. Because the manager's compensation portfolio structure before the jump in tail risk is highly correlated with his or her portfolio immediately afterwards, we can use this predetermined payoff structure to analyze how option-based convexity affects managerial responses to an increase in risk, thereby avoiding concerns about reverse causality.

Focusing on a short window of three years after risk increases and excluding any firm-years after CEO turnover (because the pre-existing portfolio corresponds to a different CEO and is thus less informative in those cases), we find that the convexity of a managers' pre-existing, equity-based incentives is positively related to the increase in their firms' risk after a carcinogen is discovered. On average, exposed firms' stock variance increases by about 0.10 after the jump in tail risk, and exposed firms whose CEOs face high vega see the largest increase in stock variance - a one standard deviation greater vega is associated with a 50\% larger increase in the stock variance. This finding suggests that managers with more convex payoffs are less likely to take actions to offset the increase in left-tail risk and provides the most definitive evidence to date that the convexity of managerial pay packages directly affects managerial choices with respect to corporate risk.

We also explore the specific financing and investment choices managers make that affect firm risk and find that these choices are also related to managers' portfolios. Gormley and Matsa (2011) find 
that the average firm responds to a jump in tail risk by reducing leverage and diversifying through acquisitions of cash-rich firms. We explore heterogeneity in these responses. We find that CEOs with high portfolio vegas reduce leverage less than CEOs in other exposed firms. Similarly, we observe significantly less stockpiling of cash by CEOs with higher vegas. Convex payoffs also appear to make CEOs less likely to engage in diversifying acquisitions and less aggressive in cutting back on risky investments, as captured by smaller cuts in their firms' R\&D expenses.

Our findings do not appear to be driven by omitted variables, which could be a problem if factors that are correlated with the initial choice of compensation structure also affect how a firm responds to the increase in tail risk for reasons unrelated to compensation. For example, highly risk-averse managers might respond more aggressively to reduce risk after tail risk increases. If firms compensate highly riskaverse managers with less option-based pay, then this might explain the observed correlation between convexity and changes in financial and investment decisions. However, theory suggests more risk-averse CEOs might actually be given payoffs that are more convex to mitigate the moral hazard problem arising from their risk-aversion (e.g., Guay, 1999). ${ }^{8}$ Our results for vega are also robust to controlling for manager fixed effects and interactions of exposure with various measures that are likely to be correlated with managerial risk tolerance, including corporate financial vulnerability, external governance, and CEO age and tenure.

Taken together, these results suggest that the structure of managerial compensation has important effects on corporate responses to tail risk and that the convex payoffs provided by options do affect risktaking incentives. In particular, options can increase a firm's overall risk by reducing managers' incentives to undertake risk-reducing activities when facing a jump in left-tail risk. Relative to stock, risktaking incentives from options' convexity appear to reduce the sensitivity of a manager's expected utility to deviations from the manager's desired level of risk.

Our paper addresses two distinct, but connected, questions regarding managerial compensation and risk: how do firms' risky investment opportunities affect boards' choices regarding stock-based pay

\footnotetext{
${ }^{8}$ On the other hand, firms might need to offer more risk-averse CEOs less convex payoffs to attract them in the first place.
} 
and how do convex payoffs affect managers' risk-taking incentives? The interconnectedness of these questions makes it challenging to answer either question. Identifying how boards adjust pay is difficult given the lack of exogenous changes in firms' risky investment opportunities. As a result, prior research typically relies on market-to-book ratios as a measure of growth opportunities (e.g., Smith and Watts, 1992; Core and Gauy, 1999) or on regulatory changes that affect managers' incentives to invest in risky projects (Cohen, Dey, and Lys, in press). Likewise, identifying how convex payoffs affect managers' risk-taking incentives is complicated by the lack of exogenous changes in such payoffs. Our paper takes a new approach to these two questions by analyzing an exogenous increase in tail risk that directly affects shareholders' investment opportunities.

The remainder of the paper is organized as follows. Section 2 discusses how managers' portfolios respond to tail risk and illustrates how shocks to tail risk can be used to identify options' effect on managerial risk-taking. Section 3 discusses our empirical setting, data sources, and identification strategy. Section 4 analyzes how boards adjust equity-based incentives in response to an unanticipated change in tail risk. Section 5 examines the managers' responses to increased risk as a function of their existing compensation contract. Section 6 concludes with a discussion of the broader implications of our work.

\section{Theoretical framework}

This paper develops a novel way to use unanticipated shocks to business risk to examine how the structure of managers' compensation portfolios both responds to changes in firms' background risk and affects managerial risk-taking. In this section, we first discuss why managers' portfolios might respond to changes in risk and why these responses pose an identification challenge to many estimates in the existing literature. We then show how unanticipated increases in risk can be used to identify both this response and compensation's effect on risk taking.

\subsection{Endogeneity of managers' compensation portfolios to background risk}

The riskiness of firms' investment opportunities is widely thought to be an important determinant of managers' compensation. Firms often face investment opportunities that have positive net present value but feature significant idiosyncratic risk. Because risk-averse managers may be reluctant to take 
such risky projects, boards can use convex payoffs to induce managers to do so (e.g., Hirshleifer and Suh 1992; Dittmann and Yu 2011; Edmans and Gabaix 2011). This motive for providing convexity is strongest for firms with many risky investment opportunities, including growth options (Guay 1999), and thus might lead to a positive association between convexity and firm risk.

In our empirical analysis, we examine how managers' portfolios respond to the increase of a particular type of risk, left-tail risk. Unlike a mean-preserving increase in risk, which maintains the net present value of existing projects, an increase in left-tail risk decreases the expected cash flows (and NPV) by boosting the probability of a very negative outcome. The left-tail risk reduces the chance that shareholders will receive proceeds from the firm's future investments and affects the manager personally through any undiversified wealth that is tied to the value of the firm. As such, a left-tail risk will likely lead both boards and managers to adjust the portfolio vega and the portfolio delta.

Boards have multiple reasons to decrease managers' portfolio vega and portfolio delta after lefttail risk increases. By reducing shareholders' expected cash flows from new investments, the left-tail risk reduces shareholders' willingness to pursue marginal projects, thereby reducing the need to provide a risk-averse manager with an incentive to undertake as many risky investments. ${ }^{9}$ In this scenario, boards have reason to reduce managers' compensation vega. The decrease in desired investments also reduces the need for delta (Smith and Watts 1992), as do other factors. Risk-averse executives may require a greater premium for holding stock-based pay, which could also lead firms to shift compensation to other forms. Finally, reducing managers' exposure to firm risk, by reducing their stock-based pay, can also mitigate agency conflicts arising from managers' risk aversion (Jensen and Meckling 1976; Amihud and Lev 1981; Holmström 1999), which are particularly acute in the presence of left-tail risk (Gormley and Matsa 2011).

Managers also have a personal incentive to limit their financial exposure to their firms' risk. Lefttail events, such as bankruptcy and employment loss, can lead to severe personal losses, including the loss of private benefits, reputation, and wealth tied to the firm. The most direct way managers can limit their exposure to these risks is to alter their financial portfolio (e.g., by exercising options or selling

\footnotetext{
${ }^{9}$ Indeed, Gormley and Matsa (2011) find evidence that shareholders prefer managers to pay out the excess cash through dividends and stock repurchases following the increase in tail risk described in Section 3.
} 
unrestricted stock). To the extent that CEOs influence their own pay, they might also shift their compensation away from stock and options. These changes may lower both vega and delta. Furthermore, managers can modify the firms' risk directly by altering corporate investment (Gormley and Matsa, 2011).

These effects of risk highlight the endogenous nature of the managers' compensation contracts. Because firms' risk environment affects the structure of managers' contracts and because option-based pay may in turn affect risk-taking incentives, it is difficult to identify either causal effect by simply comparing measures of risk-taking to managers' portfolio vega and delta. As we describe next, unanticipated shocks to tail risk can be used to overcome these identification challenges.

\subsection{Identification based on shocks to business risk}

It is straightforward to see how an exogenous increase in business risk can be used to identify how firms' risk affects the structure of managers' compensation portfolios. Under plausible assumptions, the shock to business risk also allows us to identify how the structure of managers' compensation portfolios, including their convexity, affects managers' risk-taking.

To illustrate how we identify the effect of convex payoffs on risk-taking, we derive the expected utility and marginal expected utility with respect to risk for a manager with different portfolios. Following Lambert et al. (1991), we model a portfolio as a combination of cash, stock, and options that provides a risky payoff, $Z(P)$, at the end of the period, and this payoff is a function of the firm's stock price, $P$. This portfolio can be thought of as the combination of both past and current compensation paid to the manager by the firm's shareholders, along with the manager's outside wealth (including cash, real estate, or other investments), which is not tied to the firm's performance. The stock price $P$ is assumed to be a random variable with cumulative probability distribution $F(P)$ and density function $f(P)$, and is bounded below by zero. Letting $U(x)$ represent the manager's utility when his or her total payoff is $x$, the manager's expected utility can be expressed as

$$
\int_{0}^{\infty} U(Z(P)) f(P) d P
$$


In this framework, we analyze a manager's expected utility under different portfolios of stock and options. We assume the manager has a power utility function with a coefficient of relative risk aversion of two. Similar to the Black-Scholes model, we assume that the firm's stock return follows a lognormal return process, and following Lambert et al. (1991), we assume an initial stock price of $\$ 50$, annual expected return of 0.10 per year, and an annual variance of returns $\sigma^{2}$.

For simplicity, we analyze the manager's expected utility under two possible portfolios: one with only options and the other with only stock. The options portfolio contains 50,000 options. The options are assumed to expire in ten years and have a 20 percent probability being in the money at expiration. The stock portfolio contains 2,500 shares of stock. The particular numbers of options and shares ensure that the two portfolios provide the manager with the same expected utility when at the risk level that maximizes expected utility; in other words, the manager's participation constraint is satisfied equally by the two portfolios. In both cases, the portfolio accounts for one-third of the manager's total wealth. We use a positive affine transformation to rescale the utility functions so that the maximum utility is equal to ten. Figure 1 plots the manager's expected utility as a function of the firm's stock return variance under the two different portfolios.

The two expected utility functions in Figure 1 illustrate how options' convex payoffs (vega) can influence the manager's optimal level of risk-taking. As shown in Figure 1, the level of stock variance that maximizes a manager's expected utility depends on the manager's portfolio; the optimal stock variance for the manager with the options portfolio is greater than it is with the stock portfolio. The manager's optimal stock variance is chosen to balance incentives from the payoff's convexity and his or her risk aversion. For a given increase in risk, the increased value of a convex portfolio increases the manager's expected utility, but risk aversion reduces it. At low levels of risk, the gains in expected utility from the portfolio's convexity exceed the losses from risk aversion, providing a net incentive for the manager to take on greater risk. The prior literature has focused on this relationship between the amount of convexity in the payoff structure (vega) and the desired level of risk-taking. ${ }^{10}$

\footnotetext{
${ }^{10}$ Although the options portfolio increases risk-taking incentives in this example, this need not always be the case. As shown by Lambert et al. (1991), Carpenter (2000), and Ross (2004), options - particularly those deep in-themoney - also make a manager's wealth sensitive to stock price movements (i.e., options also increase delta), which can reduce risk-taking incentives.
} 
A portfolio's convexity also affects the "risk-curvature" of the manager's expected utility, where risk-curvature is defined as the manager's marginal utility with respect to risk. For example, note the riskcurvature of the manager's expected utility around the optimal levels of risk in Figure 1; the expected utility of the manager with options is flatter around the peak than that of the manager with stock. The difference in risk-curvature arises from the convexity-risk aversion tradeoff. An increase in volatility reduces a manager's expected utility because the manager is risk averse, but convex compensation mitigates this reduction in expected utility because the convexity boosts the expected value of the compensation as volatility increases. The same intuition holds in reverse for reductions in volatility; a manager with more convex payoffs experiences smaller changes in expected utility when risk decreases. ${ }^{11}$

Our paper exploits this novel connection between payoff convexity and risk-curvature to design an empirical test that links managers' compensation convexity to risk-taking. Rather than examine the relationship between convexity (vega) and the level of risk-taking directly, as in the prior empirical literature, our identification strategy instead examines the relationship between convexity and the change in risk-taking after firms' risk unexpectedly increases. Put in terms of the manager's expected utility as a function of risk (Figure 1), we relate risk-taking behavior to convexity-driven differences in riskcurvature at the peak rather than to convexity-driven differences in the location of the peak. Our thought experiment is as follows: assume that a manager has already chosen the level of risk that maximizes his or her expected utility given the current compensation arrangement; what happens when the firm's risk environment unexpectedly changes?

When the risk environment changes, the convexity of the manager's potential payoffs also changes. Theoretically, the effect of an increase in left-tail risk on the convexity of an option's payoff structure is ambiguous. The partial derivatives of vega with respect to volatility and stock price, where vega is measured as the sensitivity of the value of the managers' options to stock price volatility (following Core and Guay, 2002), can be positive or negative depending on other parameters. Strictly

\footnotetext{
${ }^{11}$ Like the effect of options on a manager's desired level of risk, the effect of options on a manager's sensitivity to deviations in risk is also theoretically ambiguous because options provide exposure to stock price movements (i.e., delta) in addition to convexity. In our example, the convexity effect dominates.
} 
speaking, the stock portfolio's convexity is also affected by the increase in tail risk, but the effect is small and will not be picked up by this definition of vega (Guay, 1999; Core and Guay, 2002).

The convexity of the manager's payoffs prior to the unexpected change in risk, however, is a positive predictor of convexity immediately after the change in risk. In Figure 2, we plot the vega for each portfolio after risk changes. To match our empirical setting, we model this change in risk as an increase in left-tail risk. (The analysis is similar when the increase in stock return variance is mean-preserving; see Appendix B). Specifically, we examine an increase in the probability of a stock price realization below $\$ 10$; we plot the effect of increases in this probability of between zero and five percentage points. A five percentage point increase in the probability of a price below $\$ 10$ roughly represents a doubling of that probability. ${ }^{12}$ Our analysis is robust to varying the size of the shock in both scope (the price below which realization probabilities increase) and scale (the size of the probability increase). As shown in Figure 2, the vega of the option portfolio declines after left-tail risk increases but remains greater than the vega of the stock portfolio, which equals zero irrespective of the tail-risk.

This difference in the portfolios' convexity affects risk-taking incentives after tail risk increases. Figure 3 plots the manager's marginal expected utility with respect to volatility after left-tail risk increases. Marginal expected utility is plotted separately for the stock and option portfolios. The manager's marginal expected utility is negative for both portfolios but is smaller in magnitude for the more convex portfolio. In other words, the convex portfolio provides the manager with less incentive to reduce the firm's stock price volatility after risk increases. This difference in incentives relates to the riskcurvature of expected utility around its peak and to the underlying convexity-risk aversion tradeoff. A risk-averse manager, irrespective of his or her portfolio, gains from reducing risk, but this gain is less when reducing risk also reduces the expected value of convex payoffs. If it is costly or simply difficult to adjust the firm's risk, this effect of convexity makes the manager less responsive to the firm's changing risk environment.

\footnotetext{
${ }^{12}$ An increase in left-tail risk also reduces a firm's overall value and stock price. In this example, a five percentage point increase in the probability of a price below $\$ 10$ reduces the firm's stock price by about $5.25 \%$.
} 
As illustrated by Figures 2 and 3, the pre-existing differences in convexity largely persist after risk increases and affect managers' risk-taking incentives. Our empirical tests, therefore, relate managers' responses to their pre-existing pay structure. We measure their pay structure prior to risk unexpectedly increasing because these incentives are predetermined and highly correlated with their incentives immediately afterwards, which we do not observe directly in our empirical setting. The ex post vega and delta that we do observe might already be affected by managers' endogenous responses, including adjustments to financial leverage, cash holdings, R\&D, and acquisitions. By affecting firm risk, these managerial actions also affect the convexity of managers' own payoff structure, thereby making it difficult to identify the direction of causality when relating managers' actions to the ex post level of convexity. $^{13}$

By focusing on how vega is related to responses to unanticipated increases in risk, rather than absolute levels of risk-taking, our empirical approach allows us to avoid the concerns about reverse causality that plague the existing literature. Traditionally, researchers have compared the vega of managers' portfolios to measures of firm risk, but as shown in Section 4, the firms' risk environment influences boards' choices regarding managers' equity-based pay. Absent exogenous shocks to managers' option-based incentives, this reverse causality poses an identification challenge for the traditional estimation approach. Because our approach focuses instead on how vega affects responses to increased risk, avoiding concerns about reverse causality only requires that the increase in risk be unanticipated.

Thus, our approach to identify convexity's effect on risk-taking requires the same assumptions as would be required to use the ex ante payoff structure as an instrument for the unobserved ex post payoff structure that motivates managers' risk-taking: ${ }^{14}$

1) The portfolio vega (portfolio delta) immediately prior to risk increasing is positively correlated with the portfolio vega (portfolio delta) immediately afterward.

\footnotetext{
${ }^{13}$ Figures 2 and 3 also illustrate why it is appropriate to focus on ex post levels of vega rather than on the changes in vega caused by the increase in left-tail risk. Even though vega decreases more when the manager holds options (Figure 2), the manager has less incentive to reduce risk when he or she holds options (Figure 3), because the manager still has a higher vega after risk increases than when he or she holds stock.

${ }^{14}$ Note that we cannot use the increase in liability risk itself as an instrument for vega and delta, because the increase itself boosts stock volatility, thereby violating the exclusion restriction.
} 
2) The increase in left-tail risk is unanticipated.

3) The portfolio vega and portfolio delta immediately prior to risk increasing are not correlated with variables that also affect companies' responses to the increased risk.

The first assumption allows us to use the ex ante portfolio vega and portfolio delta as proxies for the unobserved ex post portfolio vega and portfolio delta that drive risk-taking incentives. The second assumption enables us to rule out reverse causality, and the third assumption pertains to omitted variables. Unlike the traditional empirical approach, which must assume the absence of unobservable factors that affect both managers' portfolios and firms' risk, our assumption is narrower. In order for an unobserved variable to be problematic in our setting, it must affect both managers' portfolios and how firms respond to unanticipated changes in risk. We evaluate and rule out potential confounders in robustness tests reported in Section 5.

\section{Empirical setting}

In this paper, we analyze left-tail risk that is created when a chemical to which a firm's workers have already been exposed is newly identified as a carcinogen. The discovery increases both the liability and regulatory risks of the firm. Using data on workplace exposures to known carcinogens, historical damage awards, and historical cash flows, Gormley and Matsa (2011) find that a typical legal liability faced by firms with such workplace exposures is around $5 \%$ of assets, and that such a shock would increase the median probability of distress among exposed firms by 30 -fold. The possibility that future regulation might limit the use of these chemicals and significantly increase a firm's cost of doing business further increases the risk of future distress. See Gormley and Matsa (2011) for a more detailed description of the liability and regulatory risks associated with workplace exposures and why firms cannot easily insure or protect themselves from these risks.

Identifying workers' exposure to newly identified carcinogens requires the combination of information on (1) scientific discoveries related to chemical carcinogenicity and (2) which firms use these chemicals. Following Gormley and Matsa (2011), we use the National Toxicology Program's (NTP) 
Report on Carcinogens $(R o C)$ for information about the timing of discoveries and the National Occupational Exposure Survey (NOES) to identify firms in which workers were likely to have been exposed to these chemicals. We considered various other data sources, including International Agency for Research on Cancer monographs, California Proposition 65, and the Environmental Protection Agency's Integrated Risk Information System. We chose to rely on the $R o C$ because each edition is comprehensive, because it provides a long time series, and because U.S. law requires firms to monitor the list. For example, firms are required to warn employees about their exposure to substances that are included in the RoC [U.S. Government Regulation 29 CFR, parts 1910.1200(b)(1) and (d)(4)]. Although the RoC is not updated annually, Gormley and Matsa (2011) find that firms respond only after chemicals are added to the list.

We determine whether a firm is affected by the listing of a newly classified carcinogen based on the firm's SIC code in Compustat in the year prior to each new listing. ${ }^{15}$ We consider a firm to be affected if it operates in a 4-digit SIC code in which at least $5 \%$ of workers were observed to be exposed to the carcinogen in the NOES. The 5\% cutoff captures 32 unique chemical additions to the $R o C$ after 1983 and roughly the top third of observed exposures at the industry level, corresponding to the discoveries that are most likely to result in increased legal liability and future distress. ${ }^{\mathbf{1 6}}$

Our data on firms' financials are from Compustat, and our data on executive compensation are from Yermack (1995) and Execucomp. Yermack (1995) covers the approximately 800 firms listed by Forbes magazine as among the 500 largest U.S. public corporations in the years 1984-1991, and Execucomp covers about 3,000 S\&P 1,500 firms in the years 1992-2008. Our main measures of a CEO's payoff structure are the sensitivities of the CEO's firm-related wealth to stock price movements and to stock price volatility. We calculate a manager's sensitivity to stock price movements (delta) from his or her portfolio of stock and options using the Core and Guay (2002) definition — the dollar change in wealth

\footnotetext{
${ }^{15}$ To accomplish this, we first convert the NOES data, which are reported using the SIC-1972 coding scheme, to the SIC-1987 coding scheme used by Compustat, by applying an employee-weighted concordance table from the Bureau of Labor Statistics (1989). We then determine which firms were affected by an increase in tail risk based on Compustat's historical measure of a firm's industrial classification.

${ }^{16}$ We use a lower cutoff than do Gormley and Matsa (2011) because of the relatively small number of exposed firms for which compensation data are available.
} 
experienced by the manager for a $1 \%$ increase in the firm's stock price. We calculate the sensitivity to stock price volatility (vega) using the dollar change in wealth experienced by the manager for a 0.01 increase in the volatility of a firm's stock price. This measure of sensitivity has been used to measure a manager's incentive to take risks (e.g., Guay, 1999; Habib and Ljungqvist, 2005). Both incentive measures are expressed in thousands of dollars. Details on the construction of all variables are in Appendix A.

To ensure a consistent sample of observations across specifications, we exclude observations with missing values for the inputs necessary to calculate the manager's delta and vega in the year prior to a chemical being added to the $R o C$. In all, 143 firms with both financial and compensation data are affected by a newly identified carcinogen, and these increases in tail risk occur for different firms in 1985, 1989, 1991, 2000, and 2004. These firms operate in 43 different 4-digit SIC industries and span 21 of the 48 Fama and French (1997) industries. (Fama-French industries are collections of 4-digit SIC industries that are meant to represent broader industry categories.)

For each new chemical listing in the $R o C$, we construct a comparison group of unaffected firms (firms without observed exposures to any newly listed carcinogens) that were present in the same FamaFrench industry classification as one of the affected firms. To ensure an adequate control sample in each industry, we drop both affected and unaffected observations in Fama-French industries in which there is not at least one unaffected firm for every ten affected firms. (Our findings are robust to using other exclusion thresholds.) This yields a comparison sample of 341 unexposed firms in 82 SIC industries.

Firms with exposures to the newly identified carcinogens are strikingly similar to our sample of unexposed firms before the listing of a new carcinogen. Ex ante characteristics of firms with exposures are reported in column (1) of Table 1, and the ex ante characteristics of firms without exposures are reported in column (2). Even though we match firms based only on Fama-French industries, the two groups are similar in average stock variance, size, market-to-book, and profitability. Annual compensation and equity-based incentives, as measured by log total pay and the fraction of pay given as options, are also similar across the two groups of firms. The differences in delta and vega of managers' 
full portfolio of options and stock are less than one-tenth and one-eighth of a standard deviation, respectively. ${ }^{17}$ As shown by the $p$-values reported in column (3), we are unable to reject the null hypothesis that exposed and unexposed firms are similar in all of these dimensions before risk increases.

As in Gormley and Matsa (2011), the use of the NOES likely introduces a degree of measurement error in our ability to identify firms with potential exposures, possibly leading us to underestimate the true effect of tail risk. There are two main measurement issues. First, the NOES only provides data on exposures at the 4-digit industry level; firm-level data is not available. Our subsequent analysis implicitly assumes that all firms in the industry are affected and calculates the average effect. If not all firms in the industry are affected, then we are underestimating the true average effect of the increase in tail risk. Second, firms may have stopped using a dangerous chemical after the NOES was completed in 1983 but before the chemical's listing in the $R o C$. Whereas firms would still be liable for past exposures, the increase in liability risk would be smaller in such cases. Despite these measurement concerns, Gormley and Matsa (2011) present evidence to suggest that the NOES indeed captures exposures that later become significant liability and regulatory risks.

An analysis of firms' stock volatility suggests that the liability and regulatory risks associated with these exposures are salient. Figure 4 plots the annualized daily variance of exposed and unexposed firms' stock returns, relative to the year before a new chemical is added to the $R o C$. Whereas exposed and unexposed firms' stock variances track each other quite closely before the carcinogen comes to light, they diverge sharply afterward with stock variance increasing by about $60 \%$ among exposed firms. The sharp change in volatility after a chemical is added to the $R o C$ confirms that new $R o C$ listings correctly capture the timing of increases in business risk.

Gormley and Matsa (2011) analyze corporate responses to this increase in risk. They find that firms, especially those with weak balance sheets, tend to respond to such risks by acquiring large, unrelated businesses with relatively high operating cash flows. The diversifying growth is primarily funded with equity, thereby reducing overall financial leverage, and appears to be motivated primarily by managers' personal exposure to their firms' risk in that the growth has negative announcement returns

\footnotetext{
${ }^{17}$ The standard deviations of portfolio delta and portfolio vega are 2,179 and 120.8 , respectively.
} 
and is related to firms' external governance, institutional ownership, and inside ownership, as measured using the share of the firm's stock held by the firm's management team. The analysis here directly examines the role of CEOs' compensation, its convexity, and its effect on risk-taking incentives. In particular, we examine how quickly boards change the structure of CEOs' compensation to reflect the new risk environment, and we exploit CEOs' pre-existing stock and options holdings (that were awarded before the manifestation of the tail risk) to analyze whether the convexity of managers' payoff structure is related to risk-taking incentives.

\section{How business risk affects the structure of managerial compensation}

To examine how compensation structures respond to increased tail risk, we compare changes in the exposed and unexposed firms' managers' compensation structures after a new carcinogen is listed in the $R o C$. We first analyze the immediate impact of business risk on the structure of managers' annual compensation (which we will refer to as compensation "flows") and on managers' decisions to exercise options. We then analyze the long-term impact on managers' overall portfolio vega and portfolio delta and the impact on the starting-year vega and delta of newly hired managers.

\subsection{Effects of exposure on flow vega, flow delta, and options exercised}

To examine how the structure of compensation flows respond to increased tail risk, we construct a cohort of exposed and unexposed firms using firm-year observations for the three years before and the three years after the listing for each year that new carcinogens are listed. We start with three-year windows to examine how compensation changes in the immediate aftermath of the increase in tail risk. Firms are not required to be in the sample for the full six years around the listing. We then pool the data across cohorts (i.e., across all new carcinogen listings) and estimate the average treatment effect using a stacked difference-in-differences estimation similar to Gormley and Matsa (2011). Specifically, we estimate the following firm-panel regression:

$$
\text { Incentives }_{i j c t}^{\text {flow }}=\beta_{0}+\beta_{1} \text { Exposure }_{j c t}+\omega_{t c}+\gamma_{i c}+\varepsilon_{i j c t} \text {, }
$$

where Incentives flict is one of several dependent variables of interest related to the structure of the chief 
executive's compensation flow for firm $i$ in year $t$, and Exposure is an indicator that equals one if at least $5 \%$ of employees in cohort $c$ and industry $j$ were observed to be exposed in the NOES to a known $R o C$ listed carcinogen as of year $t$. For an exposed firm, this indicator changes from 0 to 1 when the chemical is identified as a carcinogen. We include firm-cohort fixed effects, $\gamma_{i c}$, to ensure that we estimate the impact of exposure after controlling for any fixed differences between firms; we include year-cohort fixed effects, $\omega_{t c}$, as a non-parametric control for any secular time trends. Gormley and Matsa (in press) show that such fixed effects, rather than other ad hoc transformations of the dependent variable commonly used in the literature, are the correct way to control for unobserved group heterogeneities. We allow the firm and year fixed effects to vary by cohort because this approach is more conservative than including simple fixed effects. In our baseline specification, we deliberately do not control for any time-varying accounting variables because these variables are likely to be affected by the increase in tail risk, and their inclusion could thus confound estimates of $\beta_{1}{ }^{18}$ In any event, the results are robust to the inclusion of standard controls, as reported in the tables below. To account for potential covariance among firm outcomes within the same 4-digit SIC code and over time, we adjust the standard errors for clustering at the industry level.

After tail risk increases, there are two primary ways for a manager's financial exposure to the firms' stock price and volatility to change: changes initiated by the company's board and changes initiated by the manager. First, the board can modify the options and stock components of the manager's current pay. We measure these adjustments using the vega and delta of managers' current year compensation and refer to these sensitivities as "flow vega" and "flow delta" for short. Second, the manager can modify his or her exposure by exercising vested options and/or selling unrestricted stock. We examine both types of changes in Table 2 .

We find that boards do in fact modify the incentive structure of managers' annual compensation after tail risk increases. Specifically, they reduce the annual compensation's sensitivities to both return volatility and price. Controlling only for firm-cohort and year-cohort fixed effects, the CEOs' flow vega

\footnotetext{
${ }^{18}$ Because the increase in tail risk is exogenous, $\beta_{1}$ in Eq. (2) measures the change in the dependent variable caused by the increased tail risk. If we include endogenous controls, then $\beta_{1}$ might be biased (Angrist and Pischke, 2009, pp. 64-66).
} 
decreases, on average, by $\$ 7,600$ per 0.01 increase in the firm's stock return volatility (column $1 ; p<$ 0.05 ), and the flow delta decreases by about $\$ 12,900$ per $1 \%$ increase in equity value (column $4 ; p<$ 0.01). The declines in flow vega and flow delta are robust to additional controls for firm size, CEO tenure, and the CEO's total cash compensation (columns 2 and 5). ${ }^{19}$ These decreases are also not driven by CEO turnover; significant drops in both flow incentives remain after excluding ex post observations from both the affected and comparison samples for which a different CEO is in control than in the year before the listing (columns 3 and 6).

The declines in vega and delta are consistent with boards responding to the decline in risky investment opportunities that shareholders wish to pursue. Because the increase in left-tail risk reduces the expected cash flows from many risky investments, boards have reason to use less convex payoffs and fewer stock-based incentives. The declines could also reflect other considerations, as discussed in Section $2.1^{20}$

Managers of exposed firms also take actions to directly reduce their own financial exposure to their firms' risk. In the three years after tail risk increases, CEOs of exposed firms sharply increase the value of options they exercise relative to CEOs of unexposed firms by more than $\$ 1$ million, after controlling for size, tenure, and cash compensation (column $8 ; p<0.01$ ). The increase in the value of options exercised is robust to excluding observations for which a different CEO is present than in the year before the $\mathrm{RoC}$ listing (column 9). In unreported results, we also find a decrease in the number of shares owned by managers of exposed firms of about 30,000, suggesting these managers may be selling shares in addition to exercising options, but the estimate is noisy and not statistically significant (the standard error is about 85,000 shares).

\footnotetext{
${ }^{19}$ Our control variables in this and later specifications follow Hayes et al. (2012). All of the variables are defined in Appendix A.

${ }^{20}$ Some caution is warranted before interpreting the decline in convexity after risk increases as evidence that boards in our sample want CEOs to engage in risk-reducing activities, like diversifying acquisitions, rather than just to curtail future investments. Further analysis finds that the reduction in vega is greater among managers with an above-median vega. Even after the reductions, these managers' average vega remains higher than that of other exposed firms and discourages these managers from engaging in the value-destroying, risk-reducing activity documented in Gormley and Matsa (2011).
} 
The timing of these changes coincides with the increase in tail risk. Figure 5 plots point estimates from a modified version of Eq. (2), where we allow the effect of Exposure to vary by year from three years before risk increases until three years afterward. ${ }^{21}$ The relative changes in flow vega (flow delta) are in the top (middle) panel. There is no indication of a decrease in flow vega or flow delta prior to the increase in tail risk, but afterward, firms with exposure to a newly identified carcinogen tend to reduce their CEO's flow vega and flow delta relative to other firms. These reductions begin the year risk increases and stay lower thereafter.

The timing of the increase in options exercised by managers at exposed firms, presented in the bottom panel of Figure 5, is striking as well. The value of options exercised is practically flat in the years before tail risk increases; before the chemical is added to the $R o C$, managers of exposed firms appear no more likely than do managers of other firms to increase or decrease the number of options exercised. Then as soon as risk increases, managers of firms with exposure to a newly identified carcinogen start exercising options more than do other managers. These managers exercise an additional $\$ 2$ million in options relative to managers of similar unexposed firms in the year that risk increases and exercise an additional \$1 million the following year.

The precise timing of these exercise decisions and the changes in flow vega and flow delta suggest that they are in fact caused by the increase in tail risk, rather than by any omitted characteristic related to the manager, firm, or industry. The timing of these changes also confirms that firms and their managers did not anticipate the chemicals' addition to the $R o C$; if anticipated, we would expect the incentive changes and option exercising to begin prior to the chemical being added to the $R o C$.

These findings highlight the potential for reverse causality in prior studies of CEO incentives and their effect on corporate risk-taking. A firm's choice to use stock- and option-based incentives depends on its risk environment, so a correlation between equity-based incentives and firm risk may reflect the effect of the firm's risk environment on its choice of incentives or vice versa. This joint determinedness of incentives and a firm's risk raises concerns about previous identification strategies that implicitly or explicitly assume the firm's risk environment has no effect on the choice of incentives.

\footnotetext{
${ }^{21}$ This analysis examines a longer panel of five years before Exposure. The point estimates reported in Figure 5 are estimated relative to the excluded years $T-4$ and $T-5$.
} 


\subsection{Long-term effects of exposure on portfolio vega and portfolio delta}

We next analyze the long run changes in the vega and delta of managers' accumulated compensation portfolios - what we call the "portfolio vega" and the "portfolio delta." Table 3 presents results from regressions examining the overall change in portfolio vega and portfolio delta in the years after risk increases. Specifically, we estimate the following firm-level regression:

$$
\text { Incentives }_{i j c[t=T+k]}^{\text {porffilo }}-\text { Incentives }_{i j[[t=T-1]}^{\text {portfolio }}=\gamma_{1} \text { Exposure }_{j c[t=T+k]}+\delta_{c}+\varepsilon_{i j c} \text {, }
$$

where Incentives portfolio $_{i j[t=T+k]}-$ Incentives $_{i j[t[T-T-1]}^{\text {porfflio }}$ is the change in portfolio vega or portfolio delta from the year before a chemical is added to the $\operatorname{RoC}$ (i.e., $t=T-1)$ to $k$ years after the chemical is added $(t=T+k)$ for the CEO of firm $i$ in industry $j$ and cohort $c$; Exposure $_{j c[t=T+k]}$ is defined as before; and $\delta_{c}$ is a cohort (or, equivalently, year) fixed effect. To focus on how the shift in flow vega, flow delta, and exercising activity affect the portfolio vega and portfolio delta of the existing CEO, we exclude observations in which the CEO in year $T+k$ was not in office in year $T-1$. We analyze the change in portfolios for newly appointed CEOs below. The standard errors are again adjusted for clustering at the industry level.

We find that the changes in the composition of new compensation awards and in managers' exercising behavior seem to lower CEOs' portfolio vega or portfolio delta three years after tail risk increases, but the declines are not statistically significant. Our point estimate for the three-year decrease in portfolio vega is about $\$ 25,000$ per 0.01 increase in a firm's stock volatility, which is about one-fifth of a standard deviation (Table 3, column 1). The three-year decrease in portfolio delta is about $\$ 180,000$ per $1 \%$ increase in equity value, or about one-fourth of a standard deviation, for managers of exposed firms relative to other managers and relative to their own deltas before risk increases.

Decomposing the exposed firms' vega after risk increases illustrates the sources of these changes and the relative importance of already-granted stock and options. CEOs' portfolio vega after tail risk increases can be written as the combination of three components:

$$
\operatorname{veg} a_{i j c[t=T+k]}^{\text {porffolio }}=v e g a_{i j c[t=T+k]}^{\text {pre }}+v e g a_{i j c[t=T+k]}^{\text {flow }}-\operatorname{veg} a_{i j c[t=T+k]}^{\text {exercised }}
$$

where $v e g a_{i j[t=T+k]}^{p r e}$ is the vega in year $T+k$ of the compensation portfolio held by CEO $i$ in industry $j$ and 
cohort $c$ in year $T-1, \operatorname{veg}_{i j[t[T+k]}^{\text {flow }}$ is the vega of options accumulated through the CEOs' annual compensation flows between years $T$ and $T+k$, and $v e g a_{i j c[t=T+k]}^{\text {exrcised }}$ is the vega of options exercised by the CEO between years $T$ and $T+k$. To estimate how much each of these sources contribute to the changes in vega, we restrict attention to the Execucomp sample, due to data availability. Further details on these calculations are in Appendix C.

We find some evidence of exposed CEOs' portfolio vega decreasing after risk increases, similar to our findings in the full sample. Figure 6, Panel A plots the average portfolio vegas for managers of exposed and unexposed firms. While there appears to be no change in portfolio vega among unexposed firms over the period, the exposed firms' portfolio vega drops in the year that tail risk increases and continues to decrease in subsequent years. The cumulative decline in year $T+2$ is about one-third of a standard deviation, but similar to the full sample (reported in Table 3, Column 1), it is not statistically significant at conventional levels $(p=0.15)$.

The breakdown of the portfolio vega into its three components reveals the importance of managers' pre-existing portfolio after tail risk increases. As shown in Panel B of Figure 6, the pre-existing portfolio still accounts for almost half of exposed CEOs' portfolio vega three years after tail risk increases. The continued importance of the pre-existing portfolio may not be surprising in that vesting schedules restrict managers' ability to exercise their options and because it is costly for firms to modify securities that have already been awarded. The ongoing influence of the pre-existing portfolio suggests that the decline in flow vega and flow delta described above take time to significantly affect the portfolio vega and portfolio delta.

The breakdown shown in Figure 6, Panel B, however, does not allow us to ascertain what proportion of the average drop in portfolio vega is driven by each of the three components. For example, does the pre-existing portfolio vega decline at a greater rate or do vega flows accumulate more slowly? To answer this question, we construct a counterfactual of what the three components would have been absent the increase in risk. The counterfactual assumes that managers exercise the same number of options as in year $T-1$ and that the pre-existing portfolio vega and the flow vega change at the same rate as for unexposed firms. 
Relative to this counterfactual, we find that the newly granted compensation's lower vega increasingly contributes to the average decline in vega over time. The estimates are displayed in Figure 6, Panel C. We attribute about a third of the observed drop in CEOs' portfolio vega three years after the increase in left-tail risk to the decline in CEOs' pre-existing portfolio vega, about $60 \%$ to the reduction in annual flows, and about $6 \%$ to increased options exercising. ${ }^{22}$ The relative contribution of each source varies over time. In the first year, more than half of the decline in portfolio vega is from the CEOs' preexisting portfolio, while only about one-third is from the flow vega and $10 \%$ is from the increased exercising.

This diminishing role of the pre-existing portfolio suggests that the reduced flow vega and flow delta have greater impacts over time. Table 3 reports longer-term changes in portfolio vega and portfolio delta. We find a statistically significant decline in managers' portfolio delta beginning in year four. In the fourth year after tail risk increases, the portfolio delta is about $\$ 350,000$ per $1 \%$ increase in equity value lower for managers of exposed firms relative to other managers and relative to their own deltas before risk increases (column 4; $p<0.05$ ). This decline is about half of a standard deviation in exposed firms' portfolio delta. By the fifth year, portfolio delta decreases by about $\$ 450,000$ per $1 \%$ increase in equity value (column $6 ; p<0.10$ ). Beginning in the sixth year after tail risk increases, we also find a statistically significant decline in portfolio vega. The six-year change in portfolio vega is about $\$ 55,000$ per 0.01 increase in a firm's stock volatility, which is about $40 \%$ of a standard deviation for exposed firms (column $7 ; p<0.10)$.

\subsection{Effects of exposure on the vega and delta of newly-hired managers}

If a manager's existing portfolio impedes his or her portfolio incentives from adjusting quickly, then one would expect portfolio incentives for new CEOs to exhibit a different pattern. Because new CEOs typically enter these positions with relatively small portfolios of company stock and options, their portfolio incentives should respond quickly after risk increases. To analyze this, we estimate a

\footnotetext{
${ }^{22}$ The positive contribution of the existing portfolio to the decline in vega indicates that, on average, the increase in stock volatility and decrease in stock price caused by the increase in left-tail risk cause a drop in the portfolio vega of exposed CEOs relative to the drop observed for unexposed CEOs. This is consistent with the decline in vega observed in the theoretical example for a CEO with options (see Figure 2). While not presented in Figure 6, we also find that the increase in left-tail risk reduces the average delta of CEOs' pre-existing portfolios.
} 
specification similar to Eq. (2) using only observations from new CEOs' first year. This estimation indicates whether Exposure is associated with different initial incentives for new CEOs. Because there are not many firms with a new CEO in the three years both before and after tail risk increases, we do not include firm-cohort fixed effects in these specifications. To control for possible baseline differences in the portfolios of newly hired CEOs in exposed and unexposed industries, we include an indicator variable for industry-cohorts that experience an increase in tail risk. The results are reported in Table 4.

After tail risk increases, newly hired CEOs are given compensation portfolios that exhibit lower exposure to firm risk. The portfolio vega is almost $\$ 50,000$ lower, or about a third of a standard deviation, for a 0.01 increase in the standard deviation of stock returns for newly hired CEOs of exposed firms relative to other newly hired CEOs (column $1 ; p<0.10$ ). The lower portfolio vega is robust to controlling for firm size, cash compensation, and CEO tenure (column $2 ; p<0.10$ ).

After risk increases, new CEOs of exposed firms are also paid with lower vegas than are the CEOs they replaced. To examine within-firm changes, we compare the portfolio vega of the new CEO with that of the prior CEO. Columns 3 and 4 of Table 4 present results for the difference in portfolio vega between the new $\mathrm{CEO}$ and the prior CEO. After controlling for changes in firm size, cash compensation, and CEO tenure, the portfolio vega of a newly hired CEO of an exposed firm is about $\$ 85,000$, or almost two-thirds of a standard deviation, lower than that of the previous CEO, relative to the change at unexposed firms (column $4 ; p<0.10$ ).

\section{How the structure of managerial compensation affects corporate risk-taking}

Our finding that CEOs' portfolios respond to changes in firms' risk environment highlights a key challenge in identifying a causal effect of incentives on corporate risk-taking. A correlation between managers' portfolio convexity and firm risk could reflect the effect of the convexity on managers' risktaking or it might reflect the effect of firms' background risk on boards' choices regarding pay.

The unanticipated increase in tail risk provides an opening to overcome this identification challenge. To the extent that managers are motivated by financial incentives, portfolio vega and portfolio delta affect responses to the increase in risk. As shown in Section 2.2, risk-averse managers with convex 
payoff structures will have less to gain from reducing risk since doing so will also decrease the expected value of their convex payoffs. Using the ex ante vega as a proxy for the (unobserved) vega managers face after risk increases but before they respond, we are able to identify an effect of convexity on risk-taking incentives that avoids the reverse causality critique. ${ }^{23}$

To analyze the relationship between incentives and risk-taking, we augment our estimation framework to allow for a differential effect of exposure based on managers' portfolio vega and portfolio delta in the year before tail risk increases. Given the persistence of portfolio vega and portfolio delta (see section 4.2), we focus on a short window of three pre-risk and three post-risk years, and exclude any firmyears after a CEO turns over to ensure the pre-determined compensation structure is a valid proxy for the ex post incentives. Specifically, we estimate the following firm-panel regression:

$$
\begin{aligned}
y_{i j c t} & =\lambda_{0}+\lambda_{1} \text { Exposure }_{j c t}+\lambda_{2} \text { Exposure }_{j c t} \times \phi\left(\operatorname{Vega}_{i j c[t=T-1]}\right) \\
& +\lambda_{3} \text { Exposure }_{j c t} \times \phi\left(\text { Delta }_{i j c[t=T-1]}\right)+\omega_{t c}+\gamma_{i c}+\varepsilon_{i j c t},
\end{aligned}
$$

where $y_{i j c t}$ is one of several dependent variables of interest related to corporate risk-taking, $V e g a_{i j c[t=T-1]}$ and Delta $i j c[t=T-1]$ correspond to managers' portfolio delta and portfolio vega in the year prior to tail risk increasing, and Exposure and the various fixed effects are defined as above. To ease the interpretation of the estimates, $V e g a_{i j c[t=T-1]}$ and Delta $i j c[t=T-1]$ are normalized by their sample standard deviations and demeaned with respect to their sample means before they are interacted with Exposure (i.e., $\left.\phi(X)=\left(X-\mu_{X}\right) / \sigma_{X}\right)$. Therefore, $\lambda_{1}$ represents the effect of exposure on a firm with average portfolio vega and average portfolio delta, and $\lambda_{2}\left(\lambda_{3}\right)$ represents the incremental effect of exposure for a standard deviation increase in vega (delta). The standard errors are again adjusted for clustering at the industry level.

We include both vega and delta in the specification to disentangle option grants' competing effects on risk-taking incentives. On one hand, options' convex payoffs can encourage risk-taking because the manager shares all of the gains with shareholders but not all of the losses (Jensen and Meckling, 1976; Myers, 1977; Smith and Stulz, 1985; Haugen and Senbet, 1981; Smith and Watts, 1992;

\footnotetext{
${ }^{23}$ We cannot directly observe the incentives immediately after the increase in left-tail risk because we only observe the year, and not the exact day, in which left-tail risk increases.
} 
Gaver and Gaver, 1993; Bizjak et al., 1993; Guay, 1999; Core and Guay, 1999). Vega — the sensitivity to stock volatility - provides a measure of this convexity. On the other hand, holding options also increases a manager's sensitivity to stock price movements - delta - and to the firm's tail risk, which can discourage risk-taking (Lambert et al., 1991; Carpenter, 2000; Ross, 2004). Because the portfolio vega and portfolio delta are likely to be positively correlated, a failure to control for a manager's portfolio delta may confound the effect we are interested in — the effect of options-based convexity on risk-taking after the increase in tail risk.

The inclusion of firm-cohort fixed effects, $\gamma_{i c}$, controls for time-invariant factors, like the managers' risk tolerance, that might be correlated with the predetermined levels of vega and delta. Because we exclude observations after CEOs exit, these fixed effects also effectively control for manager fixed effects. We do not report estimates for the main effects, $V e g a_{i j c[t=T-1]}$ or Delta $a_{i j[t=T-1]}$, because they are, by construction, time-invariant and perfectly collinear with the firm-cohort fixed effects. The coefficient on Exposure $_{j c t} \times V e g a_{i j c[t=T-1]}$ captures the differential response for high-vega versus low-vega exposed firms relative to the similar differential response for unexposed firms. The Exposure $_{j c t} \times$ Delta $_{i j c[t=T-1]}$ coefficient has an analogous interpretation.

We first examine stock variance as a summary measure of firms' risk-taking. A firm's stock variance captures both exposed firms' increase in tail risk and any corporate choices, such as lower leverage and fewer R\&D expenditures, that offset this increase in risk. The estimates are reported in Table 5. On average, the increase in tail risk is associated with a 0.10 increase in variance for firms with an exposure (column 1). The increase is large in magnitude (almost half of the sample mean and about a third of the sample standard deviation) and statistically significant when we add time-varying controls for firms' size, leverage, $\mathrm{R} \& \mathrm{D}$ expenditures, and market-to-book ratio (column $3 ; p<0.10) .{ }^{24}$

The increase in firms' risk is significantly larger among firms whose manager had a high portfolio vega before the increase in left-tail risk. A one standard deviation increase in a manager's portfolio vega is associated with a 0.05 larger increase in stock variance after a chemical is added to the

\footnotetext{
${ }^{24}$ The sample mean stock variance is 0.23 with a standard deviation of 0.29 . The sample mean stock volatility, another measure of firms' risk, is 0.42 with a standard deviation of 0.22 . These summary statistics are similar to those of the samples analyzed in other papers (e.g., Hayes et al., 2012).
} 
RoC. Given that there is no reason to expect the increase in liability and regulatory risk from workplace exposures to be larger for firms with a higher ex ante vega, this finding suggests that managers with more convex payoffs are less likely to take actions to offset the unanticipated increase in left-tail risk.

The larger increase in firms' risk among managers with a high portfolio vega appears to result from a smaller reduction in financial and investment risk following the increase in tail risk. In analysis reported in Table 6, we examine firms' leverage and cash management policies as a function of their managers' incentives. The increase in tail risk is associated with a reduction in leverage for the average firm (column 1), but the decline is only statistically significant for firms with a low vega manager; ${ }^{25}$ a one standard deviation increase in a manager's portfolio vega is associated with about a 1 percentage point smaller reduction in leverage (column $2 ; p<0.10$ ).

Firms' cash holdings also exhibit a differential response based on the convexity of managers' payoffs. For the average firm, the increase in tail risk is associated with an increase in the ratio of cash to assets (column 4; not statistically significant), and a lower portfolio vega is associated with a larger increase in cash holdings (column $5 ; p<0.01$ ). This differential buildup in cash is robust to including controls for firms' size, leverage, R\&D expenditures, and market-to-book ratio (column 6), but the differential response in leverage is no longer statistically significant with controls for firms' size, profitability, and R\&D expenditures, and property, plant, and equipment (column 3). ${ }^{26}$ The association between portfolio delta and risk-taking after the increase in tail risk is the opposite. A higher delta is associated with a larger reduction in leverage (columns 2-3) and larger increase in cash holdings (columns 5-6). ${ }^{27}$

Firms' investment policies also appear to be affected by the CEO's portfolio incentives. In analysis reported in Table 7, we examine firms' research and development expenditures and acquisition

\footnotetext{
${ }^{25}$ Gormley and Matsa (2011) find that the decline in leverage is statistically significant for the average Compustat firm. The estimate here is not statistically significant because our sample size is considerably smaller, as our analysis also requires data on the CEOs' compensation portfolios.

${ }^{26}$ Again, our choice of controls in all specifications follows Hayes et al. (2012). Still, caution is warranted when interpreting estimates from specifications that include these endogenous controls, because their inclusion can confound the true causal effect (see footnote 18).

${ }^{27}$ The findings for portfolio delta are consistent with Gormley and Matsa (2011), who find that larger inside ownership, as measured by the fraction of shares owned by top managers, is associated with greater risk-reducing activities after tail risk increases.
} 
behavior. The results further highlight the importance of convexity. We find that the increase in tail risk is only weakly associated with a reduction in the ratio of R\&D expenses to assets for the average firm, but a lower portfolio vega is strongly associated with a larger reduction in $\mathrm{R} \& \mathrm{D}$ expenses (column $2 ; p<0.01$ ). We also find that the portfolio vega is negatively associated with making diversifying acquisitions after risk increases. Gormley and Matsa (2011) find diversifying acquisitions to be a primary way firms reduce risk after such an event. Managers with a one standard deviation higher portfolio vega are 2.5 percentage points less likely to make a diversifying acquisition each year after tail risk increases. Both of the differential responses in $R \& D$ and diversifying acquisitions are robust to including additional timevarying controls (columns 3 and $6 ; p<0.01$ ) and are consistent with options' convex payoffs making CEOs less aggressive in cutting back on risky investments (such as R\&D) and in increasing risk-reducing investments (such as diversifying acquisitions) after the jump in tail risk.

One possible concern with these results is that an omitted variable could be related to both a manager's ex ante incentive structure in the year before risk increases and the firm's response afterward. Our analysis of managers' compensation structures prior to the jump in tail risk relies on the assumption that the differences in compensation contracts, among firms which are otherwise comparable (as shown in Table 1), are not driven by factors that also affect firms' responses to the increase in risk. Contracts will differ between comparable firms because these contracts are chosen to satisfy many objectives in addition to setting incentives for risk-taking. For example, some firms may choose to grant more options for accounting reasons (Hayes et al., 2012). These other objectives provide ex ante variation in incentives that we exploit. But if factors correlated with these objectives also affect firms' response to a jump in risk, then our analysis might suffer from an omitted variable bias.

We evaluate a wide range of potential omitted variables, including corporate financial vulnerability, external governance, and CEO age and tenure. Gormley and Matsa (2011) find that firms with greater ex ante bankruptcy risk (as measured by Altman's $z$-score), smaller size, more leverage, lower cash flows, and no dividends are more likely to engage in diversifying growth after tail risk increases, presumably because these firms experience larger increases in the likelihood of distress. Gormley and Matsa also find differences related to firms' external governance, including the proportion 
of institutional ownership. If these factors are related to the initial choice of compensation structure, then they_rather than incentives from the compensation - might possibly explain our findings. For example, older and more seasoned executives may be better equipped to cope with a major shock to the firm's cash flows; perhaps it is simply these CEOs for which we see no meaningful risk-reducing activities?

To examine the sensitivity of our results to these possible omitted variables, we repeat our analysis of Eq. (5) for stock variance, cash, leverage, R\&D, and diversifying acquisitions but now include additional interactions between Exposure and the aforementioned list of potential omitted variables. Specifically, we include interactions between Exposure and firms' size, leverage, modified Altman's zscore, cash flows, institutional ownership, CEO tenure, CEO age, and an indicator for paying dividends; similar to the portfolio vega and portfolio delta, each of the interacted variables is measured as of the year prior to the increase in tail risk. The estimates are reported in Table 8.

There is no evidence that these potential omitted variables explain the observed correlation between portfolio vega and risk-taking activities following the jump in tail risk. A higher portfolio vega is still associated with larger increases in overall firm risk, as measured by stock variance (column $1 ; p<$ 0.10), a smaller increase in cash holdings (column $2 ; p<0.01$ ) and diversifying acquisitions (column $5 ; p$ $<0.01$ ), and a smaller reduction in leverage (column 3; $p<0.10$ ) and $\mathrm{R} \& \mathrm{D}$ (column $4 ; p<0.01$ ).

A final possibility, which we cannot completely control for directly, is that unobservable differences in managerial risk preferences explain the differential effect of vega on risk-taking. For example, it is possible that risk-tolerant managers match with riskier firms that also happen to provide more convex payoff schemes (Graham et al., 2013). If true, then it is possible that the underlying risktolerance of the CEO, rather than convexity of his or her incentives, explains the importance of portfolio vega for the observed responses.

Although we cannot rule out this possibility definitively, there are indications that it is unlikely to explain our findings. The robustness tests in Table 8 already allow for a differential effect of Exposure based on various measures of firm risk, including leverage, Altman's $z$-score, and dividends. If the interaction between vega and Exposure is being driven by some matching of risk-tolerant managers to 
riskier firms, then we would expect these additional interactions to dampen the effect of vega; they do not. Moreover, theory suggests that the optimal contract for managers with greater risk aversion is actually more convex so as to provide incentives for the agent to take on appropriate risk on behalf of the more risk-tolerant shareholders (see, e.g., Guay, 1999). If true and if unobservable risk preferences were driving our observed responses, we would expect to find vega associated with more risk-reducing activities after tail risk increases. Instead, we observe the opposite.

\section{Conclusions and implications}

Every firm is exposed to business risks, including the possibilities of large, adverse shocks to cash flows. Potential sources for such shocks abound - examples include disruptive product innovations, the relaxation of international trade barriers, and changes in government regulations. We study (1) how boards adjust CEOs' exposure to their firms' risk after the risk of such shocks increase and (2) how incentives given by the CEOs' pre-existing portfolios of stock and options affect their firms' response to this risk. Specifically, we study what happens when a firm learns that it is exposing workers to carcinogens, which increase the risks of significant corporate legal liability and costly workplace regulations.

The results presented in this paper suggest that corporate boards respond quickly to changes in their firms' business risk by adjusting the structure of CEOs' compensation, but that the changes only slowly impact the overall portfolio incentives CEOs face. After the unexpected increase in left-tail risk, corporate boards reduce CEOs exposure to their firms' risk; the sensitivities of the flow of managers' annual compensation to stock price movements and to return volatility decrease. Various factors likely contribute to the board's decision, including CEOs' reduced willingness to accept a large exposure to their firms' risk and the decline in shareholders' desired investment after left-tail risk increases. Indeed, managers act to further reduce their exposure to the firm's risk by exercising more options than do managers of unexposed firms. These changes, however, only slowly move CEOs' overall exposure to their firm's risk because the magnitude of their pre-existing portfolios continues to influence their financial exposure to the firm. 
The unanticipated increase in business risk also provides an opportunity to analyze options' causal effect on corporate risk-taking. We use CEOs' pre-existing portfolio of options and stock as a proxy for managers' portfolio immediately after the carcinogens' discovery; these incentives are predetermined with respect to the new risk environment and not subject to the reverse causality concerns that plague existing studies of compensation structure and risk. We find that CEOs with more convex payoffs tend not to offset the unexpected increase in risk through diversifying acquisitions, reducing leverage, cutting R\&D expenditures, or by building up greater cash holdings. As a result, stock variance increases the most for high vega firms after the jump in tail risk. The findings are robust to numerous robustness checks and do not appear to be driven by omitted factors that might affect both the choice of compensation and firms' responses to the increased risk.

Overall, our results show that options affect corporate risk-taking and highlight the importance of a board structuring its executives' compensation packages to induce the desired level of risk taking. In addition, our results imply the novel insight that boards should design the convexity of managers' compensation with an eye on potential changes in the company's risk environment and how their executives will respond given their compensation. As our findings illustrate, more convex payoffs can dampen managerial incentives to offset unanticipated increases in business risk. Boards interested in encouraging more aggressive responses to future increases in business risk should use less convex payoffs, whereas other boards should use more convex payoffs if responding to increases in business risk is costly and undesirable to shareholders.

\section{Appendix A. Variable definitions}

$<$ Insert Appendix Table A.1 here.>

\section{Appendix B. A mean-preserving increase in risk}

In the theoretical framework described in Section 2.2, similar changes in the pre-existing portfolio's vega and the manager's differential sensitivities to deviations in risk result if we model the 
increase in risk as a mean-preserving increase in stock price volatility rather than as an increase in left-tail risk. The portfolio vega after a mean-preserving increase in risk is plotted in Fig. B.1 for both portfolios, and the manager's marginal utility with respect to stock return volatility is plotted in Fig. B.2. The decline in the options portfolio's vega is smaller in the mean-preserving case than in the case of left-tail risk, but the decline is still greater than for the stock portfolio, which does not change (Fig. B.1). Nevertheless, similar to left-tail risk, an unexpected mean-preserving increase in stock price volatility has a smaller impact on a manager's expected utility when the manager holds options rather than stock (Fig. B.2).

The similarity is intuitive. A mean-preserving increase in volatility shifts stock volatility to the right along the expected utility curve (plotted in Figure 1), whereas the increase in left-tail risk, by reducing the expected cash flows, also shifts the manager's expected utility curve to the left. In this regard, the expected marginal utilities after each increase in risk reflect similar mappings of the utility curve's slope around the manager's optimal volatility. The difference in marginal utilities also suggests that, when a firm sets a new compensation contract, the aggressiveness with which the manager will implement the implied level of risk-taking depends on the structure of the compensation contract.

\section{Appendix C. Decomposing changes in portfolio vega}

In Section 4.2, we report estimates that decompose the changes in exposed CEOs' portfolio vega into three sources: changes in the vega of the pre-existing portfolio, additional vega from new option grants, and reduced vega from managers' exercising options. Only the Execucomp sample provides sufficient information on both existing and newly granted options to compute these estimates. The estimates are based on the following methodology, which is an extension of Core and Guay (2002).

To calculate the vega of CEOs' pre-existing portfolio of options $\left(v e g a^{\text {pre }}\right)$ in the years after lefttail risk increases, we apply the Core-Guay method to calculate the vega of CEOs' existing options as of year $T-1$ in subsequent years by holding constant the number of options and their exercise prices but adjusting for changes in their maturity, the risk-free rate, and the firm's dividend yield, stock price, and

stock volatility. To calculate the vega of CEOs' option grants after the increase in risk (vega $\left.{ }^{\text {flow }}\right)$, we 
construct the portfolio that consists of options granted after the increase in tail risk and apply the CoreGuay method to calculate the vega of this portfolio. Lastly, to calculate the vega of options exercised

(vega $\left.a^{\text {exercised }}\right)$, we construct the portfolio of exercised options and again apply the Core-Guay method to calculate the vega of this portfolio. Because Execucomp only provides the number and value of exercised options but not their maturity or exercise price, we approximate these inputs by assuming that exercised options have the same average exercise price and maturity as the CEOs' exercisable options in the previous year.

Using the three above calculations, we can reconstruct the CEOs' overall vega in the years after the increase in tail-risk. Specifically, the "implied" portfolio vega equals vega $a^{\text {pre }}+v e g a^{\text {flow }}-v e g a^{\text {exercised }}$. Despite the approximations required for these calculations, the implied vegas closely track observed vegas; for the average exposed CEO in our sample, the implied vega differs from the observed vega by only about $5 \%$.

\section{References}

Aboody, D., Barth, M.E., Kasznik, R., 2004. Firms' voluntary recognition of stock-based compensation expense. Journal of Accounting Research 42, 123-150.

Agrawal, A., Mandelker, G.N., 1987. Managerial incentives and corporate investment and financing decisions. Journal of Finance 42, 823-837.

Aggarwal, R.K., Samwick, A.A., 1999. The other side of the trade-off: The impact of risk on executive compensation. Journal of Political Economy 107, 65-105.

Amihud, Y., and B. Lev. 1981. Risk Reduction as a Managerial Motive for Conglomerate Mergers. Bell Journal of Economics 12, 605-17.

Angrist, J.D., and J. Pischke. 2009. Mostly Harmless Econometrics: An Empiricist's Companion. Princeton University Press, Princeton.

Armstrong, C.S., Vashishtha, R., 2012. Executive stock options, differential risk-taking incentives, and firm value. Journal of Financial Economics 104, 70-88.

Berger, P.G., Ofek, E., Yermack, D.L., 1997. Managerial entrenchment and capital structure decisions. Journal of Finance 52, 1411-1438. 
Bizjak, J.M., Brickley, J.A., Coles J.L., 1993. Stock-based incentive compensation and investment behavior. Journal of Accounting and Economics 16, 349-372.

Bureau of Labor Statistics, 1989. Employment data under the new standard industrial classification: First quarter 1988. U.S. Department of Labor, Washington, D.C.

Carpenter, J.N., 2000. Does option compensation increase managerial risk appetite? Journal of Finance $55,2311-2331$.

Chava, S., Purnanandam A., 2010. CEOs versus CFOs: Incentives and corporate policies. Journal of Financial Economics 97, 263-278.

Cohen, D.A., Dey, A., Lys, T.Z., in press. Corporate governance reform and executive incentives: implications for investments and risk-taking. Contemporary Accounting Research.

Coles, J.L., Daniel, N.D., Naveen L., 2006. Managerial incentives and risk-taking. Journal of Financial Economics 79, 431-468.

Core, J., Guay, W., 1999. The use of equity grants to manage optimal equity incentive levels. Journal of Accounting and Economics 28, 151-184.

Core, J., Guay, W., 2002. Estimating the value of employee stock option portfolios and their sensitivities to price and volatility. Journal of Accounting Research 40, 613-630.

DeFusco, R.A., Johnson, R.R., Zorn, T.S., 1990. The effect of executive stock option plans on stockholders and bondholders. Journal of Finance 45, 617-627.

Demsetz, H., Lehn, K., 1985. The structure of corporate ownership: Causes and consequences. Journal of Political Economy 93, 1155-1177.

Denis, D.J., Denis, D.K., Sarin, A., 1997. Agency problems, equity ownership, and corporate diversification. Journal of Finance 52, 135-160.

Dittmann, I., Yu, K., 2011. How important are risk-taking incentives in executive compensation? Working Paper.

Edmans, A., Gabaix, X., 2011. The effect of risk on the CEO market. Review of Financial Studies 24(8), $2822-2863$.

Esty, B.C., 1997a. Organizational form and risk taking in the savings and loan industry. Journal of Financial Economics 44, 25-55.

Esty, B.C., 1997b. A case study of organizational form and risk shifting in the savings and loan industry. Journal of Financial Economics 44, 57-76.

Fama, E.F., French, K.R., 1997. Industry costs of equity. Journal of Financial Economics 43, 153-193. 
Gaver, J.J., Gaver, K.M., 1993. Additional evidence on the association between the investment opportunity set and corporate financing, dividend, and compensation policies. Journal of Accounting and Economics 16, 125-160.

Gormley, T.A., Matsa, D.A., 2011. Growing out of trouble? Corporate responses to liability risk. Review of Financial Studies 24, 2781-2821.

Gormley, T.A., Matsa, D.A., in press. Common errors: How to (and not to) control for unobserved heterogeneity. Review of Financial Studies.

Graham, J., Harvey, C.R., Puri, M., 2013. Managerial attitudes and corporate actions. Journal of Financial Economics, 109, 103-21.

Guay, W.R., 1999. The sensitivity of CEO wealth to equity risk: An analysis of the magnitude and determinants. Journal of Financial Economics 53, 43-71.

Habib, M.A., Ljungqvist, A., 2005. Firm value and managerial incentives: A stochastic frontier approach. Journal of Business 78, 2053-93.

Haugen, R.A., Senbet, L.W., 1981. Resolving the agency problems of external capital through options. Journal of Finance 36, 629-647.

Hayes, R.M., Lemmon, M., Qiu, M., 2012. Stock options and managerial incentives for risk-taking: Evidence from FAS 123R. Journal of Financial Economics 105, 174-190.

Himmelberg, C.P., Hubbard, R.G., Palia, D., 1999. Understanding the determinants of managerial ownership and the link between ownership and performance. Journal of Financial Economics 53, 353-384.

Hirshleifer, D., Suh, Y., 1992. Risk, managerial effort, and project choice. Journal of Financial Intermediation 2, 308-345.

Holmström, B. 1999. Managerial Incentive Problems: A Dynamic Perspective. Review of Economic Studies 66, 169-82.

Jensen, M.C., Meckling, W.H., 1976. Theory of the firm: Managerial behavior, agency costs and ownership structure. Journal of Financial Economics 3, 305-360.

Jolls, C., 1998. Stock repurchases and incentive compensation. National Bureau of Economic Research Working Paper 6467.

Kadan, O., Swinkels, J.M., 2008. Stocks or options? Moral hazard, firm viability, and the design of compensation contracts. Review of Financial Studies 21, 451-482.

Knopf, J.D., Nam, J., Thornton Jr., J.H., 2002. The volatility and price sensitivities of managerial stock option portfolios and corporate hedging. Journal of Finance 57, 801-813.

Lambert, R.A., Larcker, D.F., Verrecchia, R.E., 1991. Portfolio considerations in valuing executive compensation. Journal of Accounting Research 29, 129-149. 
May, D.O. 1995. Do managerial motives influence firm risk reduction strategies? Journal of Finance 50, 1291-1308.

Mehran, H., 1992. Executive incentive plans, corporate control, and capital structure. Journal of Financial and Quantitative Analysis 27, 539-560.

Mehran, H., 1995. Executive compensation structure, ownership, and firm performance. Journal of Financial Economics 38, 163-184.

Myers, S.C., 1977. Determinants of corporate borrowing. Journal of Financial Economics 5, 147-1-75.

Palia, D., 2001. Endogeneity of managerial compensation in firm valuation: A solution. Review of Financial Studies 14, 735-764.

Rajgopal, S., Shevlin, T., 2002. Empirical evidence on the relation between stock option compensation and risk taking. Journal of Accounting and Economics 33, 145-171.

Rogers, D.A., 2002. Does executive portfolio structure affect risk management? CEO risk-taking incentives and corporate derivatives usage. Journal of Banking and Finance 26, 271-295.

Ross, S.A. 2004. Compensation, incentives, and the duality of risk aversion and riskiness. Journal of Finance 59, 207-225.

Saunders, A., Strock, E., Travlos, N.G., 1990. Ownership structure, deregulation, and bank risk taking. Journal of Finance 45, 643-654.

Schrand, C., Unal, H., 1998. Hedging and coordinated risk management: Evidence from thrift conversions. Journal of Finance 53, 979-1013.

Shue, K., Townsend, R., 2013. Swinging for the fences: Executive reactions to quasi-random option grants. Working Paper.

Smith, C.W., Stulz R.M., 1985. The determinants of firms' hedging policies. Journal of Financial and Quantitative Analysis 20, 391-405.

Smith, C.W., Watts, R.L., 1992. The investment opportunity set and corporate financing, dividend, and compensation policies. Journal of Financial Economics 32, 263-292.

Tchistyi, A., Yermack, D., Yun, H., 2011. Negative hedging: Performance sensitive debt and CEOs' equity incentives. Journal of Financial and Quantitative Analysis.46, 657-686.

Tufano, P., 1996. Who manages risk? An empirical examination of risk management practices in the gold mining industry. Journal of Finance 51, 1097-1137.

Yermack, D., 1995. Do corporations award CEO stock options effectively? Journal of Financial Economics 39, 237-269. 


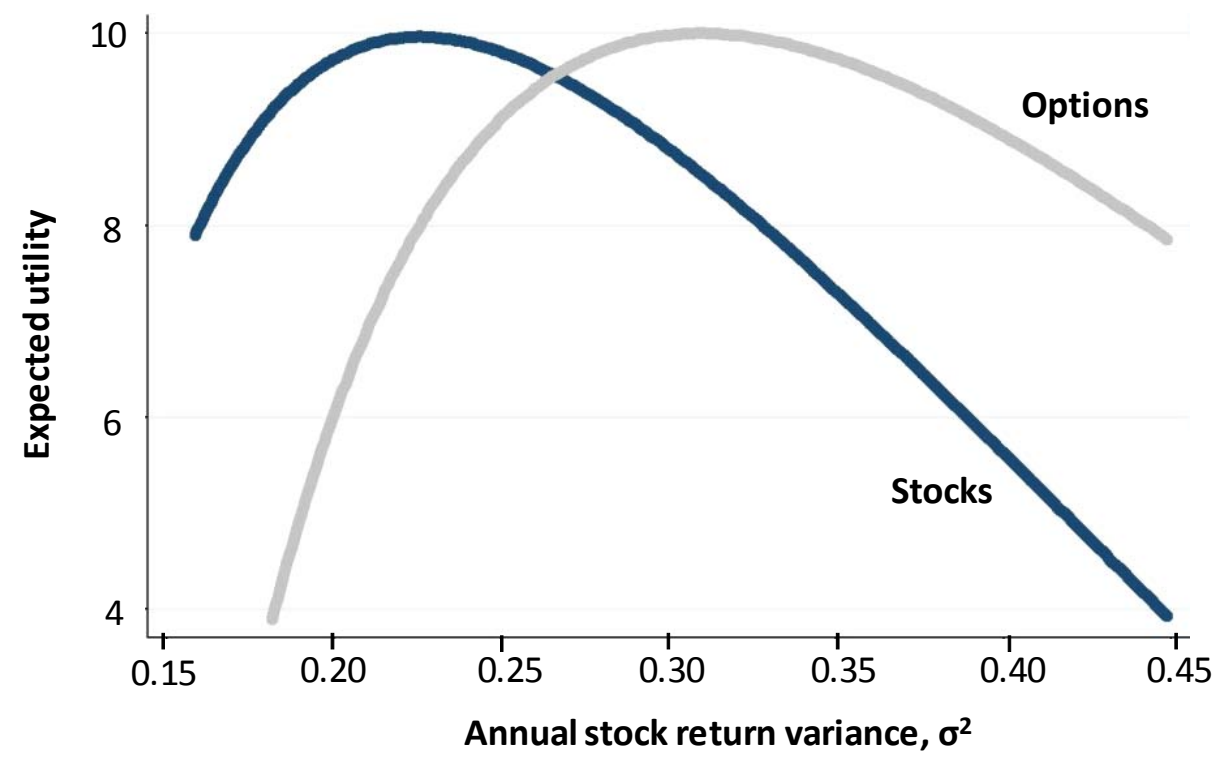

Fig. 1. Expected utility as a function of stock variance. This figure plots the expected utility of a manager as a function of the manager's portfolio and the variance of the firm's annual stock returns. The firm's stock return is assumed to follow a lognormal process with an initial price of $\$ 50$ and annual expected return of 10 percent, and the manager is assumed to have a power utility function with a coefficient of relative risk aversion of two. The options portfolio contains 50,000 options. The options are assumed to expire in ten years and have a 20 percent probability of being in the money at expiration. The stock portfolio contains 2,500 shares of stock. In both cases, the portfolio accounts for one-third of the manager's total wealth. A positive affine transformation is used to rescale the level of expected utility. 


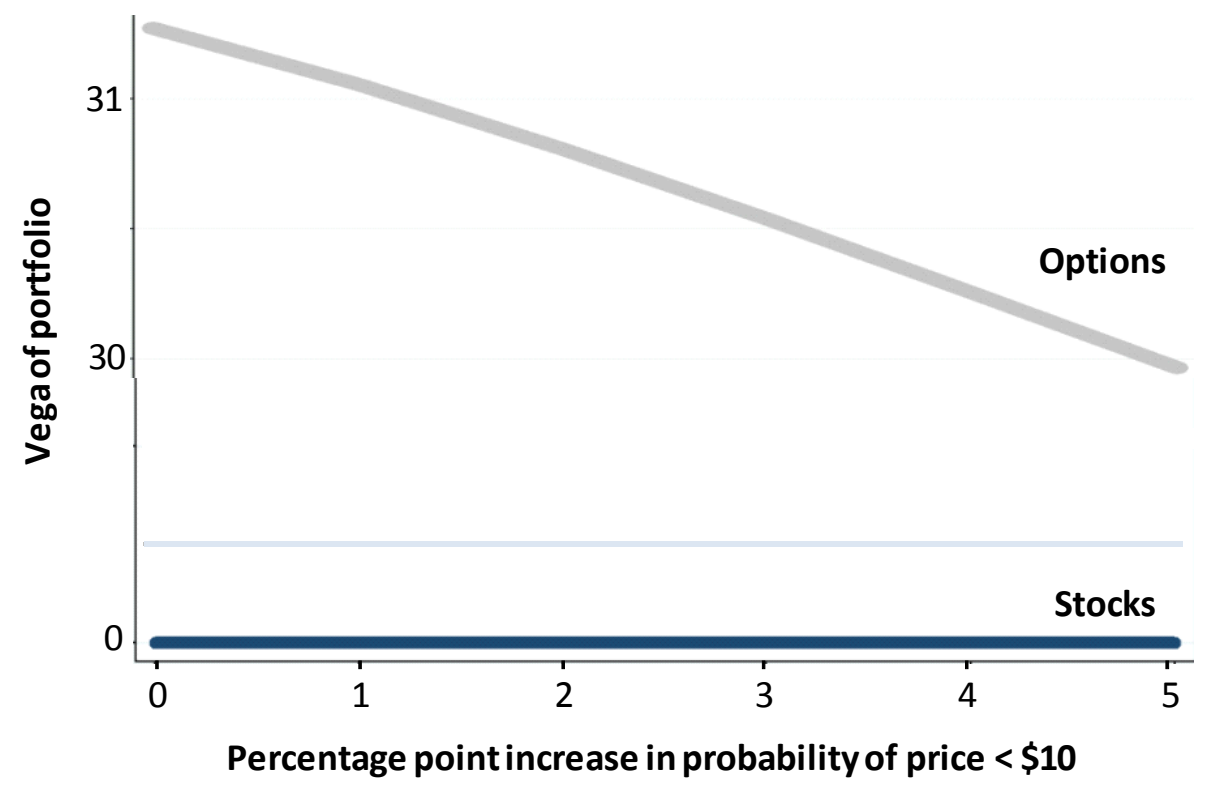

Fig. 2. Portfolio vega after an increase in left-tail risk. This figure plots each portfolio's vega after an increase in the probability of a left-tail risk, defined as an increase in the probability of a stock price realization below $\$ 10$ at the time the options expire. The portfolio vega is calculated assuming a zero dividend yield, a risk free rate of five percent, and that the firm was at the manager's optimal level of stock volatility prior to left-tail risk increasing. 


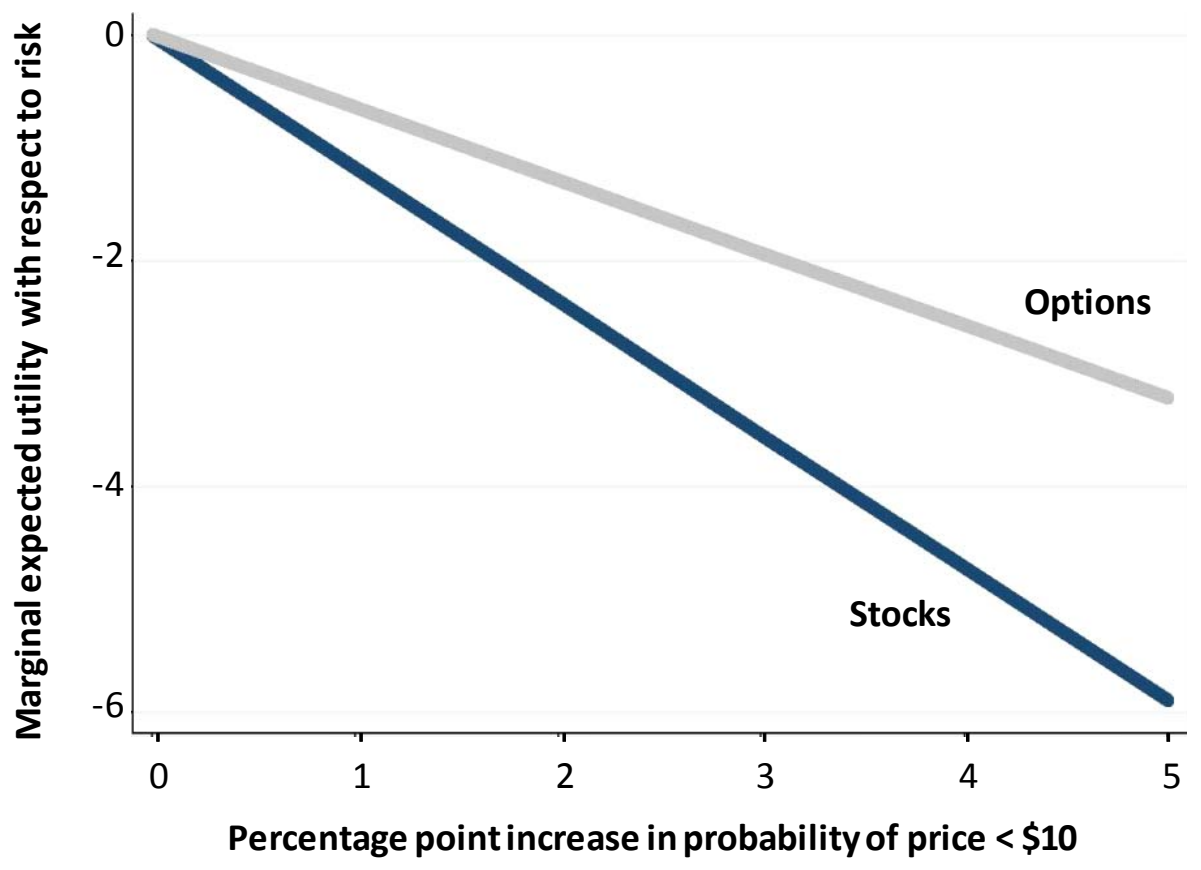

Fig. 3. Marginal expected utility of risk after an increase in left-tail risk. This figure plots the manager's marginal utility of risk after an increase in the probability of a left-tail risk, defined as an increase in the probability of a stock price realization below $\$ 10$ at the time the options expire. This is the numerical derivative of the manager's expected utility (shown in Figure 1) with respect to volatility, evaluated at the manager's previously optimal level of stock volatility. 


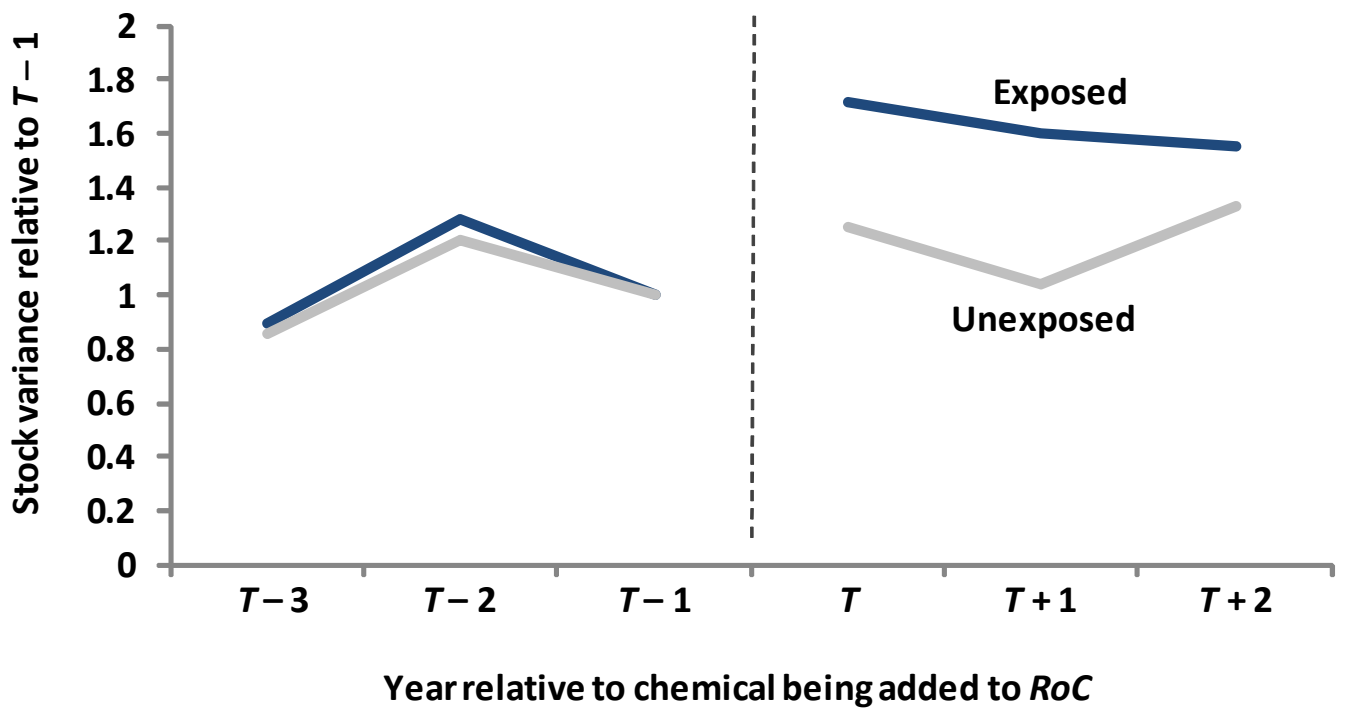

Fig. 4. Stock variance of exposed and unexposed firms. This figure plots the relative average annualized daily stock variance for exposed and unexposed firms, indexed to one in the year prior to a chemical being added to the Report on Carcinogens. 

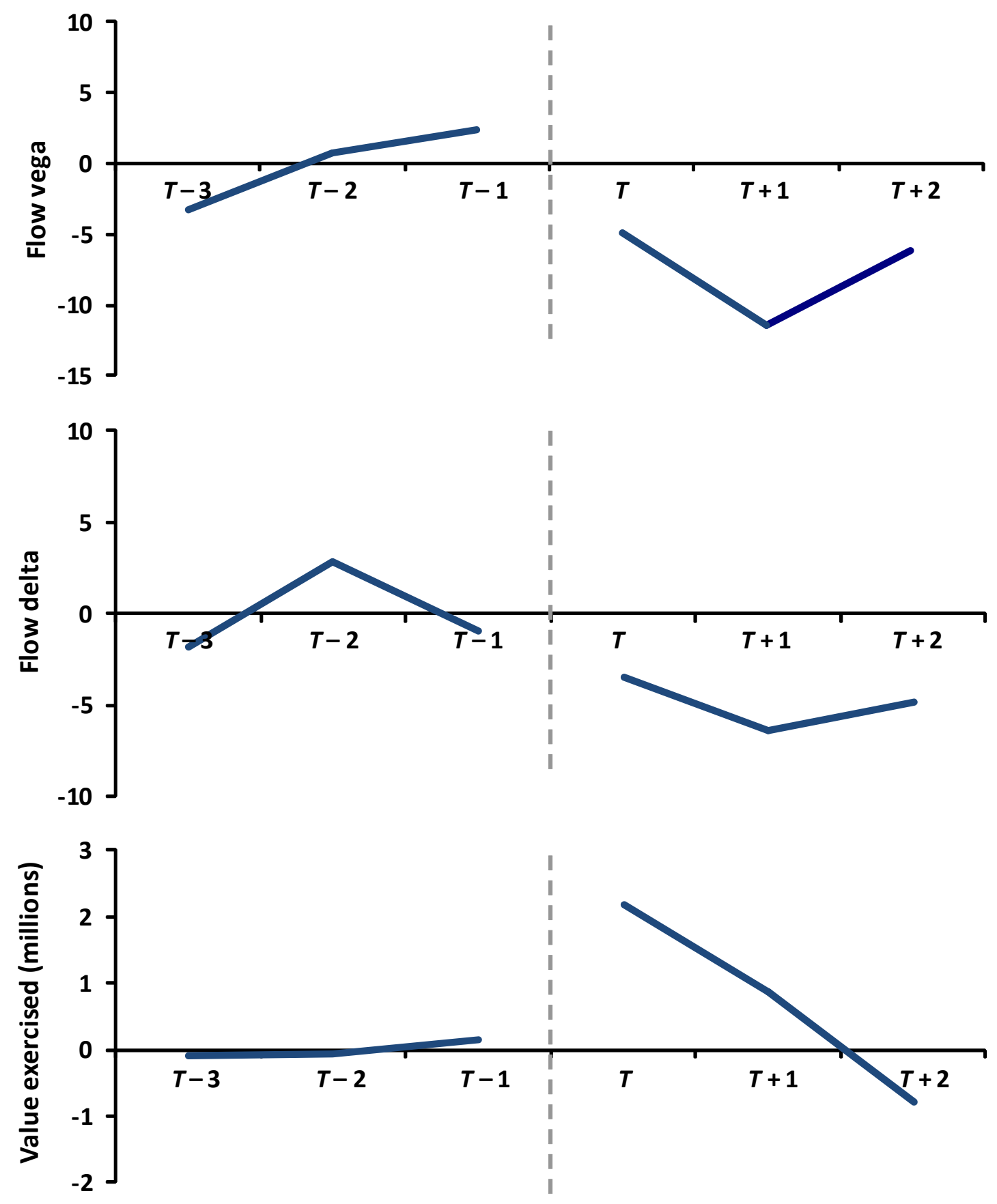

Years relative to increase in tail risk

Fig. 5. Effect of exposure on flow vega, flow delta, and the value of options exercised by year. This figure reports the point estimates from firm-panel regressions of flow vega, flow delta, and the value of options exercised on an indicator for exposure, firm-by-cohort fixed effects, and year-by-cohort fixed effects. The specifications are the same as those reported in Table 2, columns 1, 4, and 7, except that the effect of exposure is allowed to vary by year in event time. 

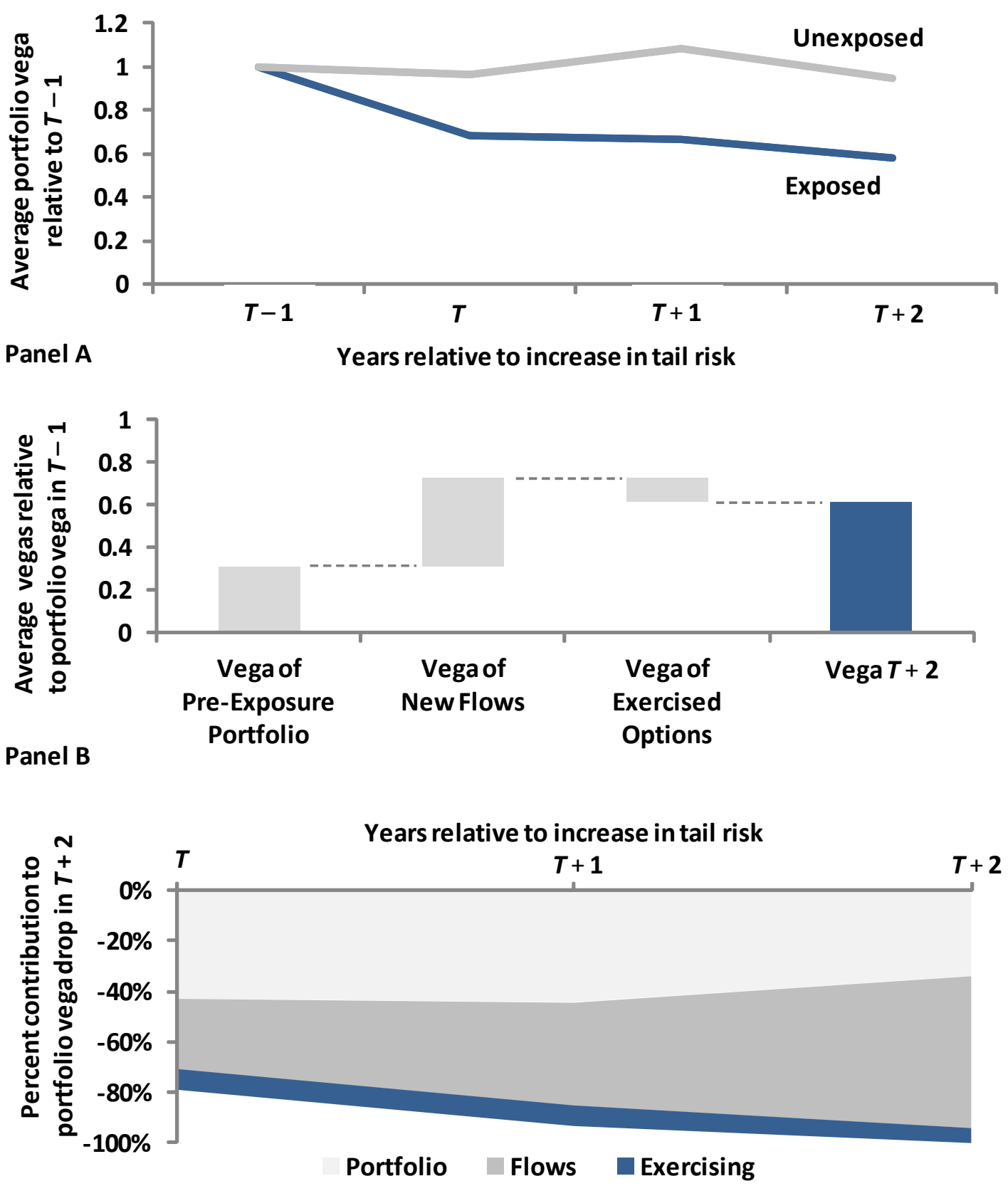

\section{Panel C}

Fig. 6. Deconstructing exposed managers' portfolio vega in year $T+2$. Panel A reports managers' average portfolio vega in exposed and unexposed firms in the Execucomp sample by year relative to the increase in tail risk. Panel B deconstructs the overall, average portfolio vega of exposed managers in year $T+2$ into its three components: vega from managers' pre-exposure portfolio, new flows, and the drop in vega from exercising of options. Panel $\mathrm{C}$ plots the percent contribution of each source to the total drop in year $T+2$ relative to the counterfactual that exposed managers continue exercising the same number of options as they did in year $T-1$ and experience the same growth rate in their preexposure portfolio vega and flow vega as unexposed managers during the same time period. 


\section{Table 1}

Ex-ante firm characteristics.

This table reports summary statistics for firm characteristics in the three years before a new chemical was added to the Report on Carcinogens. The mean and standard deviation (in parentheses) for each variable are reported separately for two samples of firms. Column 1 reports estimates for firms in 4-digit SIC industries for which more than 5\% of employees were observed to be exposed to the chemical in the 1981-1983 National Occupational Exposure Survey. Column 2 reports estimates for other firms in the same Fama-French 48-industry classification. Column 3 reports the $p$-value from a t-test of the difference between exposed and unexposed firms, where the standard errors are adjusted for clustering at the 4-digit SIC industry level. The sample is restricted to firms with nonmissing observations for portfolio vega and delta in the year prior to the new chemical being added to the Report on Carcinogens.

\begin{tabular}{ccc} 
Exposed & Unexposed & $\begin{array}{c}p \text {-value of } \\
\text { difference }\end{array}$ \\
\hline \hline$(1)$ & $(2)$ & $(3)$ \\
\hline
\end{tabular}

Firm characteristics

Stock variance

Ln(assets)

Market-to-book ratio

Cash flows / assets

\section{Compensation characteristics}

Portfolio delta

Ln(total pay)

Options / total pay
0.243

(0.211)

326.2

(716.0)

41.74

(139.5)

6.972

(0.955)
(0.088)

\subsection{7}

(0.189)

7.438

(1.396)

0.026

(0.063)

0.147

(0.092)
0.350

0.472

0.992

0.419

0.313

(0.311)
519.3

$(2,537)$

27.60

(112.2)

6.920

(1.011)

0.265

(0.254)
0.299

0.591

0.761

0.562

Observations 
Table 2

The effect of exposure on flow vega, flow delta, and options exercised.

This table reports coefficients from firm-panel regressions of flow vega, flow delta, and the value of options exercised on an indicator for exposure, firm-by-cohort fixed effects, and year-by-cohort fixed effects. Exposure equals one if more than 5\% of employees in the firm's 4digit SIC industry were observed to be exposed to a chemical listed in the most recent edition of the Report on Carcinogens (RoC), as reported in the 1981-1983 National Occupational Exposure Survey. The sample includes firm-year observations in the three years before and three years after each new chemical listing in the $R o C$ for firms with non-missing portfolio vega and delta in the year prior to the new $R o C$ listing. Columns 3,6, and 9 exclude observations after a new chemical listing for which the CEO is different than the CEO in the year prior to the chemical being listed. Columns 2-3, 5-6, and 8-9 include firms' Ln(assets) and CEOs' tenure and salary + bonus as additional controls. Standard errors, adjusted for clustering at the industry level, are reported in parentheses. ${ }^{* * *}$ significant at the $1 \%$ level; $* *$ significant at the $5 \%$ level; *significant at $10 \%$ level.

\begin{tabular}{|c|c|c|c|c|c|c|c|c|c|}
\hline \multirow[t]{2}{*}{ Dep. variable $=$} & \multicolumn{3}{|c|}{$\begin{array}{c}\text { Flow vega } \\
\text { Mean }=17.52 \\
\text { St. Dev. }=55.90\end{array}$} & \multicolumn{3}{|c|}{$\begin{array}{c}\text { Flow delta } \\
\text { Mean }=20.37 \\
\text { St. Dev. }=83.06\end{array}$} & \multicolumn{3}{|c|}{$\begin{array}{c}\text { Value of options exercised } \\
\text { Mean }=912.9 \\
\text { St. Dev. }=4,546\end{array}$} \\
\hline & (1) & (2) & (3) & (4) & (5) & (6) & (7) & (8) & (9) \\
\hline Exposure & $\begin{array}{c}-7.60 * * \\
(3.11)\end{array}$ & $\begin{array}{c}-10.00 * * * \\
(3.76)\end{array}$ & $\begin{array}{c}-8.90 * * \\
(3.89)\end{array}$ & $\begin{array}{c}-12.88 * * * \\
(4.70)\end{array}$ & $\begin{array}{c}-24.61 * \\
(13.67)\end{array}$ & $\begin{array}{l}-25.21^{*} \\
(14.40)\end{array}$ & $\begin{array}{c}790.8 \\
(575.9)\end{array}$ & $\begin{array}{c}1,063^{* * *} \\
(397.9)\end{array}$ & $\begin{array}{c}1,184^{* * *} \\
(429.2)\end{array}$ \\
\hline Observations & 2,378 & 1,367 & 1,211 & 2,363 & 1,367 & 1,211 & 2,505 & 1,439 & 1,277 \\
\hline$R^{2}$ & 0.02 & 0.05 & 0.05 & 0.01 & 0.04 & 0.05 & 0.02 & 0.09 & 0.10 \\
\hline \# of firms & 469 & 309 & 264 & 469 & 309 & 264 & 484 & 320 & 275 \\
\hline $\begin{array}{l}\text { Additional controls } \\
\text { Excludes new CEOs after } T-1\end{array}$ & & $x$ & $\begin{array}{l}x \\
x\end{array}$ & & $x$ & $\begin{array}{l}x \\
x\end{array}$ & & $x$ & $\begin{array}{l}x \\
x\end{array}$ \\
\hline \multicolumn{10}{|l|}{ Fixed effects: } \\
\hline Firm-cohort & $x$ & $x$ & $x$ & $x$ & $x$ & $x$ & $x$ & $x$ & $x$ \\
\hline Year-cohort & $x$ & $x$ & $x$ & $x$ & $x$ & $x$ & $x$ & $x$ & $x$ \\
\hline
\end{tabular}




\section{Table 3}

Long-term effect of exposure on portfolio vega and portfolio delta.

This table reports coefficients from CEO-level regressions of post-exposure changes in portfolio vega and portfolio delta on an indicator for exposure and cohort fixed effects. Exposure is defined as in Table 2. The sample includes CEOs with non-missing portfolio vega and portfolio delta in the year prior to the $R o C$ listing and excludes CEOs that are no longer present in the year in which the post-exposure change in incentives is calculated. The dependent variables are the three-, four-, five-, and six-year changes in portfolio vega and portfolio delta relative to the year prior to a chemical being added to the $R o C$. Standard errors, adjusted for clustering at the industry level, are reported in parentheses. ${ }^{* *}$ significant at the $5 \%$ level; * significant at $10 \%$ level.

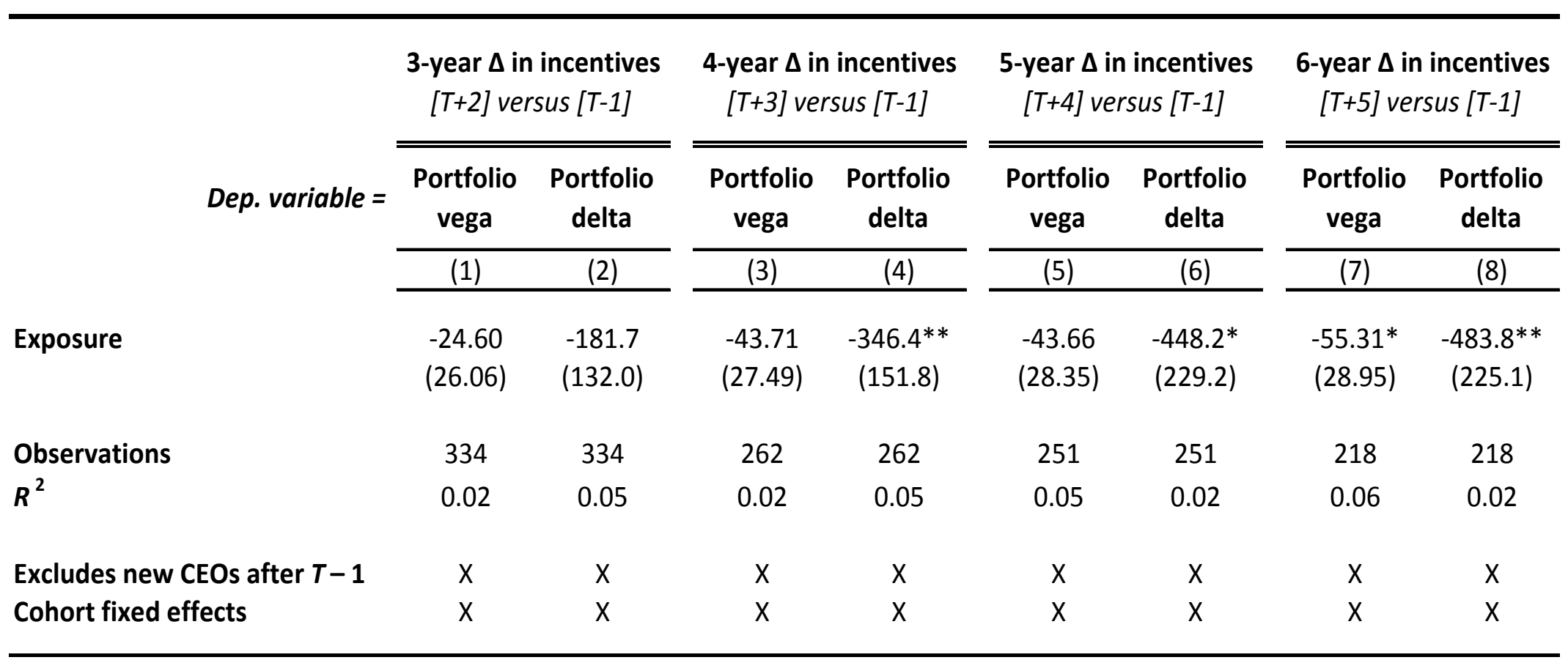




\section{Table 4}

The effect of exposure on newly hired CEOs' portfolio vega.

This table reports coefficients from CEO-level regressions of the level of and change in portfolio vega on an indicator for exposure, year-bycohort fixed effects, and an indicator for operating in an industry-cohort with an exposure. Exposure is defined as in Table 2. The sample includes observations from a CEO's first year in office for CEOs hired in the three years before and three years after each new chemical listing in the RoC. To ensure the same sample of firms as in earlier specifications, we continue to restrict the sample to firms with non-missing portfolio vega and portfolio delta in the year prior to the new $R o C$ listing. The dependent variable in columns $1-2$ is the initial portfolio vega of the newly hired CEO, and the dependent variable in columns 3-4 is the difference between the new CEO's initial portfolio vega and the portfolio vega of the outgoing CEO. Column 2 includes firms' Ln(assets) and the new CEOs' tenure and salary + bonus as additional controls, and column 4 includes the changes in these variables as controls. Standard errors, adjusted for clustering at the industry level, are reported in parentheses. *significant at $10 \%$ level.

\begin{tabular}{|c|c|c|c|c|}
\hline \multirow[t]{2}{*}{ Dep. variable $=$} & \multicolumn{2}{|c|}{$\begin{array}{l}\text { Portfolio vega of } \\
\text { newly-hired CEO }\end{array}$} & \multicolumn{2}{|c|}{$\begin{array}{l}\Delta \text { portfolio vega } \\
\text { from prior CEO }\end{array}$} \\
\hline & (1) & $(2)$ & (3) & (4) \\
\hline \multirow[t]{2}{*}{ Exposure } & $-49.4^{*}$ & $-30.3^{*}$ & -111.5 & $-84.6^{*}$ \\
\hline & $(25.8)$ & $(17.7)$ & $(67.2)$ & $(42.3)$ \\
\hline Observations & 175 & 149 & 167 & 71 \\
\hline$R^{2}$ & 0.09 & 0.45 & 0.08 & 0.36 \\
\hline Exposed industry-cohort indicator & $x$ & $x$ & $x$ & $x$ \\
\hline Year-cohort fixed effects & $\mathrm{x}$ & $\mathrm{X}$ & $\mathrm{x}$ & $x$ \\
\hline Additional controls & & $x$ & & $x$ \\
\hline
\end{tabular}




\section{Table 5}

The effects of exposure and payoff structure on firms' stock variance.

This table reports coefficients from firm-panel regressions of annualized daily stock variance on Exposure (an indicator for exposure) and its interactions with portfolio vega and portfolio delta in the year prior to an increase in tail risk, firm-by-cohort fixed effects, and year-by-cohort fixed effects. Exposure is defined as in Table 2. The sample includes firms with non-missing portfolio vega and portfolio delta in the year prior to the $R o C$ listing and excludes firm-year observations after a new chemical listing for which the CEO is different than the CEO in the year prior to the chemical being listed. For ease of interpreting the exposure coefficient and its interactions, the portfolio vega and portfolio delta are demeaned and rescaled by their sample standard deviation [i.e., $\varphi(X)=\left(X-\mu_{X}\right) / \sigma_{X}$ ] before being interacted with Exposure. Column 3 includes firms' Ln(sales), debt/assets, R\&D/sales (with missing values replaced with zeros), and market-to-book ratio as additional controls. Standard errors, adjusted for clustering at the industry level, are reported in parentheses. ${ }^{* *}$ significant at the $5 \%$ level; *significant at $10 \%$ level.

\begin{tabular}{|c|c|c|c|}
\hline Dep. variable = & \multicolumn{3}{|c|}{$\begin{array}{c}\text { Stock variance } \\
\text { Mean }=0.23 \\
\text { St. Dev. }=0.29\end{array}$} \\
\hline & $(1)$ & $(2)$ & (3) \\
\hline Exposure & $\begin{array}{c}0.102 \\
(0.068)\end{array}$ & $\begin{array}{c}0.094 \\
(0.059)\end{array}$ & $\begin{array}{l}0.097^{*} \\
(0.056)\end{array}$ \\
\hline Exposure $\times \phi\left(\right.$ Vega $\left._{T-1}\right)$ & & $\begin{array}{c}0.049 * * \\
(0.019)\end{array}$ & $\begin{array}{c}0.047^{* *} \\
(0.019)\end{array}$ \\
\hline Exposure $\times \phi\left(\right.$ Delta $\left._{T-1}\right)$ & & $\begin{array}{c}0.023 \\
(0.053)\end{array}$ & $\begin{array}{c}0.039 \\
(0.050)\end{array}$ \\
\hline Observations & 2,620 & 2,620 & 2,562 \\
\hline$R^{2}$ & 0.22 & 0.23 & 0.24 \\
\hline \# of firms & 484 & 484 & 480 \\
\hline Excludes new CEOs after $T-1$ & $X$ & $x$ & $x$ \\
\hline Additional controls & & & $x$ \\
\hline Fixed effects: & & & \\
\hline Firm-cohort & $x$ & $x$ & $x$ \\
\hline Year-cohort & $X$ & $X$ & $X$ \\
\hline
\end{tabular}


Table 6

The effects of exposure and payoff structure on firms' financial risk.

This table reports coefficients from firm-panel regressions of debt/assets and cash/assets on Exposure (an indicator for exposure) and its interactions with portfolio vega and portfolio delta in the year prior to an increase in tail risk, firm-by-cohort fixed effects, and year-by-cohort fixed effects. The specification is the same as in Table 5. For ease of interpreting the exposure coefficient and its interactions, the portfolio vega and portfolio delta are demeaned and rescaled by their sample standard deviation [i.e., $\varphi(X)=(X$ $\left.\left.\mu_{\mathrm{X}}\right) / \sigma_{\mathrm{X}}\right]$ before being interacted with Exposure. The additional controls follow Hayes et al. (2012); in column 3, they include firms' Ln(sales), EBITDA/assets, $R \& D /$ sales (with missing values replaced with zeros), and $P P \& E / a s s e t s$; and in column 6, they include firms' Ln(sales), debt/assets, $R \& D /$ sales (with missing values replaced with zeros), and market-to-book ratio. Standard errors, adjusted for clustering at the industry level, are reported in parentheses. $* * *$ significant at the $1 \%$ level; **significant at the $5 \%$ level; *significant at $10 \%$ level.

\begin{tabular}{|c|c|c|c|c|c|c|}
\hline \multirow[t]{2}{*}{ Dep. variable $=$} & \multicolumn{3}{|c|}{$\begin{array}{c}\text { Debt/assets } \\
\text { Mean }=0.25 \\
\text { St. Dev. }=0.17\end{array}$} & \multicolumn{3}{|c|}{$\begin{array}{c}\text { Cash/assets } \\
\text { Mean }=0.067 \\
\text { St. } \text { Dev. }=0.094\end{array}$} \\
\hline & (1) & (2) & (3) & (4) & (5) & (6) \\
\hline Exposure & $\begin{array}{l}-0.005 \\
(0.012)\end{array}$ & $\begin{array}{l}-0.006 \\
(0.013)\end{array}$ & $\begin{array}{l}-0.014 \\
(0.011)\end{array}$ & $\begin{array}{c}0.003 \\
(0.007)\end{array}$ & $\begin{array}{c}0.004 \\
(0.007)\end{array}$ & $\begin{array}{c}0.005 \\
(0.007)\end{array}$ \\
\hline Exposure $\times \phi\left(\right.$ Vega $\left._{T-1}\right)$ & & $\begin{array}{l}0.009 * \\
(0.005)\end{array}$ & $\begin{array}{c}0.005 \\
(0.004)\end{array}$ & & $\begin{array}{c}-0.006^{* * *} \\
(0.002)\end{array}$ & $\begin{array}{c}-0.006^{* * *} \\
(0.002)\end{array}$ \\
\hline Exposure $\times \phi\left(\right.$ Delta $\left._{T-1}\right)$ & & $\begin{array}{c}-0.056^{* *} \\
(0.023)\end{array}$ & $\begin{array}{c}-0.066^{* * *} \\
(0.018)\end{array}$ & & $\begin{array}{c}0.021^{* * *} \\
(0.006)\end{array}$ & $\begin{array}{c}0.019 * * \\
(0.008)\end{array}$ \\
\hline Observations & 2,597 & 2,597 & 2,588 & 2,230 & 2,230 & 2,210 \\
\hline$R^{2}$ & 0.03 & 0.04 & 0.11 & 0.04 & 0.04 & 0.07 \\
\hline \# of firms & 481 & 481 & 481 & 454 & 454 & 452 \\
\hline $\begin{array}{l}\text { Excludes new CEOs after } T-1 \\
\text { Additional controls } \\
\text { Fixed effects: }\end{array}$ & $x$ & $x$ & $\begin{array}{l}x \\
x\end{array}$ & $x$ & $x$ & $\begin{array}{l}x \\
x\end{array}$ \\
\hline Firm-cohort & $x$ & $x$ & $x$ & $x$ & $x$ & $x$ \\
\hline Year-cohort & $x$ & $x$ & $x$ & $x$ & $x$ & $x$ \\
\hline
\end{tabular}




\section{Table 7}

The effects of exposure and payoff structure on investment risk.

This table reports coefficients from firm-panel regressions of $R \& D / a s s e t s$ and an indicator for undertaking a diversifying acquisition on Exposure (an indicator for exposure) and its interactions with portfolio vega and portfolio delta in the year prior to an increase in tail risk, firm-by-cohort fixed effects, and year-by-cohort fixed effects. The specification is the same as in Table 5. For ease of interpreting the exposure coefficient and its interactions, the portfolio vega and portfolio delta are demeaned and rescaled by their sample standard deviation [i.e., $\varphi(\mathrm{X})=\left(\mathrm{X}-\mu_{\mathrm{X}}\right) / \sigma_{\mathrm{X}}$ ] before being interacted with Exposure. The additional controls follow Hayes et al. (2012); in column 3, they include firms' Ln(sales), sales growth, debt/assets, stock return, surplus cash/assets, and market-to-book ratio and CEOs' salary + bonus; and in column 6, they include firms' Ln(sales), EBITDA/assets, debt/assets, stock return, and market-to-book ratio, CEOs' tenure and salary + bonus, and a CEO exit indicator. Standard errors, adjusted for clustering at the industry level, are reported in parentheses. ***significant at the $1 \%$ level; ** significant at the $5 \%$ level.

\begin{tabular}{|c|c|c|c|c|c|c|}
\hline \multirow[t]{2}{*}{ Dep. variable = } & \multicolumn{3}{|c|}{$\begin{array}{c}\text { R\&D/assets } \\
\text { Mean }=0.049 \\
\text { St. Dev. }=0.048\end{array}$} & \multicolumn{3}{|c|}{$\begin{array}{c}\text { Diversifying acq. indicator } \\
\text { Mean }=0.13 \\
\text { St. Dev. }=0.34\end{array}$} \\
\hline & (1) & $(2)$ & (3) & (4) & (5) & (6) \\
\hline Exposure & $\begin{array}{l}-0.003 \\
(0.002)\end{array}$ & $\begin{array}{l}-0.004 \\
(0.002)\end{array}$ & $\begin{array}{r}-0.0003 \\
(0.002)\end{array}$ & $\begin{array}{c}0.024 \\
(0.034)\end{array}$ & $\begin{array}{c}0.029 \\
(0.036)\end{array}$ & $\begin{array}{c}0.030 \\
(0.037)\end{array}$ \\
\hline Exposure $\times \phi\left(\right.$ Vega $\left._{T-1}\right)$ & & $\begin{array}{c}0.002 * * * \\
(0.0002)\end{array}$ & $\begin{array}{c}0.001^{* * *} \\
(0.0003)\end{array}$ & & $\begin{array}{c}-0.026 * * * \\
(0.006)\end{array}$ & $\begin{array}{c}-0.022 * * * \\
(0.008)\end{array}$ \\
\hline Exposure $\times \phi\left(\right.$ Delta $\left._{T-1}\right)$ & & $\begin{array}{l}-0.002 \\
(0.002)\end{array}$ & $\begin{array}{l}0.006^{*} \\
(0.005)\end{array}$ & & $\begin{array}{c}0.055 * * \\
(0.026)\end{array}$ & $\begin{array}{c}0.034 \\
(0.035)\end{array}$ \\
\hline Observations & 1,361 & 1,361 & 1,352 & 2,645 & 2,645 & 2,576 \\
\hline$R^{2}$ & 0.06 & 0.06 & 0.18 & 0.02 & 0.02 & 0.02 \\
\hline \# of firms & 259 & 259 & 259 & 484 & 484 & 480 \\
\hline $\begin{array}{l}\text { Excludes new CEOs after } T-1 \\
\text { Additional controls }\end{array}$ & $x$ & $x$ & $\begin{array}{l}x \\
x\end{array}$ & $x$ & $\mathrm{x}$ & $\begin{array}{l}x \\
x\end{array}$ \\
\hline Fixed effects: & & & & & & \\
\hline Firm-cohort & $x$ & $x$ & $\mathrm{X}$ & $x$ & $x$ & $x$ \\
\hline Year-cohort & $x$ & $x$ & $\mathrm{X}$ & $x$ & $x$ & $x$ \\
\hline
\end{tabular}


Table 8

Controlling for possible omitted variables.

This table reports coefficients from firm-panel regressions of annualized daily stock variance, cash/assets, debt/assets, $R \& D / a s s e t s$, and an indicator for undertaking a diversifying acquisition on Exposure (an indicator for exposure) and its interactions with portfolio vega and portfolio delta in the year prior to an increase in tail risk, firm-by-cohort fixed effects, and year-by-cohort fixed effects. The specifications are the same as those reported in Tables 5-7, but also include as controls additional interactions between Exposure and various CEO and firm characteristics in the year prior to a new $\mathrm{RoC}$ listing. The following characteristics are each interacted separately with Exposure: Ln(assets), a dividend indicator, debt/assets (except for column 3), modified Altman $z$-score, cash flows/assets, institutional ownership, CEO tenure, and CEO age. Standard errors, adjusted for clustering at the industry level, are reported in parentheses. $* * *$ significant at the $1 \%$ level; **significant at the $5 \%$ level; *significant at the $10 \%$ level.

\begin{tabular}{|c|c|c|c|c|c|}
\hline Dep. variable $=$ & $\begin{array}{c}\text { Stock } \\
\text { variance }\end{array}$ & $\begin{array}{l}\text { Cash/ } \\
\text { assets }\end{array}$ & $\begin{array}{l}\text { Debt/ } \\
\text { assets }\end{array}$ & $\begin{array}{l}\text { R\&D/ } \\
\text { assets }\end{array}$ & $\begin{array}{l}\text { Diversifying } \\
\text { acquisition }\end{array}$ \\
\hline & $(1)$ & $(2)$ & $(3)$ & (4) & $(5)$ \\
\hline Exposure & $\begin{array}{c}0.147^{* * *} \\
(0.040)\end{array}$ & $\begin{array}{c}0.0221 * * \\
(0.011)\end{array}$ & $\begin{array}{l}-0.003 \\
(0.019)\end{array}$ & $\begin{array}{c}0.005 \\
(0.003)\end{array}$ & $\begin{array}{c}0.057 \\
(0.052)\end{array}$ \\
\hline Exposure $\times \phi\left(\right.$ Vega $\left._{T-1}\right)$ & $\begin{array}{l}0.026 * \\
(0.015)\end{array}$ & $\begin{array}{c}-0.006 * * * \\
(0.002)\end{array}$ & $\begin{array}{l}0.007^{*} \\
(0.004)\end{array}$ & $\begin{array}{c}0.002 * * * \\
(0.000)\end{array}$ & $\begin{array}{c}-0.033^{* * *} \\
(0.008)\end{array}$ \\
\hline Exposure $\times \phi\left(\right.$ Delta $\left._{T-1}\right)$ & $\begin{array}{c}0.039 \\
(0.043)\end{array}$ & $\begin{array}{c}0.0213^{* *} \\
(0.009)\end{array}$ & $\begin{array}{c}-0.075^{* * *} \\
(0.021)\end{array}$ & $\begin{array}{c}0.001 \\
(0.002)\end{array}$ & $\begin{array}{c}0.056 \\
(0.044)\end{array}$ \\
\hline Observations & 1,393 & 1,287 & 1,403 & 772 & 1,403 \\
\hline$R^{2}$ & 0.35 & 0.06 & 0.07 & 0.10 & 0.06 \\
\hline \# of firms & 253 & 246 & 253 & 144 & 253 \\
\hline Excludes new CEOs after $T-1$ & $x$ & $x$ & $x$ & $x$ & $x$ \\
\hline Additional Exposure interactions & $x$ & $x$ & $x$ & $x$ & $x$ \\
\hline Fixed effects: & & & & & \\
\hline Firm-cohort & $x$ & $x$ & $x$ & $x$ & $x$ \\
\hline Year-cohort & $x$ & $x$ & $x$ & $x$ & $x$ \\
\hline
\end{tabular}


Table A.1

Variable Definitions

\section{Dependent variables}

Portfolio delta

Portfolio vega

Flow delta

Flow vega

Value exercised

Cash/assets

Debt/assets

Diversifying acquisition indicator

R\&D/assets

Stock variance
Manager's change in wealth (expressed in thousands of dollars) for a $1 \%$ increase in the firm's stock price. Calculated from managers' complete portfolio of stock and options from Execucomp or Yermack (1995) using the methodology from Core and Guay (2002). The value of the option portfolio is the sum of the Black-Scholes values of the newly granted options and previously granted unexercisable and exercisable options. The Yermack sample contains information on a manager's previously granted stock but not options, so we use information only on options granted in the last year to calculate the managers' options' delta.

Manager's change in wealth (expressed in thousands of dollars) for a 0.01 increase in the annualized standard deviation of firm's stock returns. Calculated from managers' complete portfolio of stock and options from Execucomp or Yermack (1995) using the methodology from Core and Guay (2002). See the definition of Portfolio delta for more detail.

Same as Portfolio delta but calculated using only stocks and options granted in given year. In the Execucomp sample, the number of shares granted is approximated using rstkgrnt/prccf, and in the Yermack sample, it is approximated using othcomp/endprice.

Same as Portfolio vega but calculated using only options granted in given year.

Calculated as opt_exer_val in the Execucomp sample and as optgains in the Yermack sample.

Calculated from Compustat using $\mathrm{ch} / \mathrm{at}$.

Calculated from Compustat using $(d l t t+d l c) / a t$.

Calculated using SDC's Mergers and Acquisitions Database. The indicator equals one if the firm undertakes an acquisition where its primary SIC industry does not coincide with any SIC code of the target firm.

Calculated from Compustat using xrd/at.

Calculated from CRSP using the sum of squared daily returns over the year. To adjust for differences in the number of trading days, the raw sum is multiplied by 252 and divided by the number of trading days. 


\section{Firm-level controls (from Compustat)}

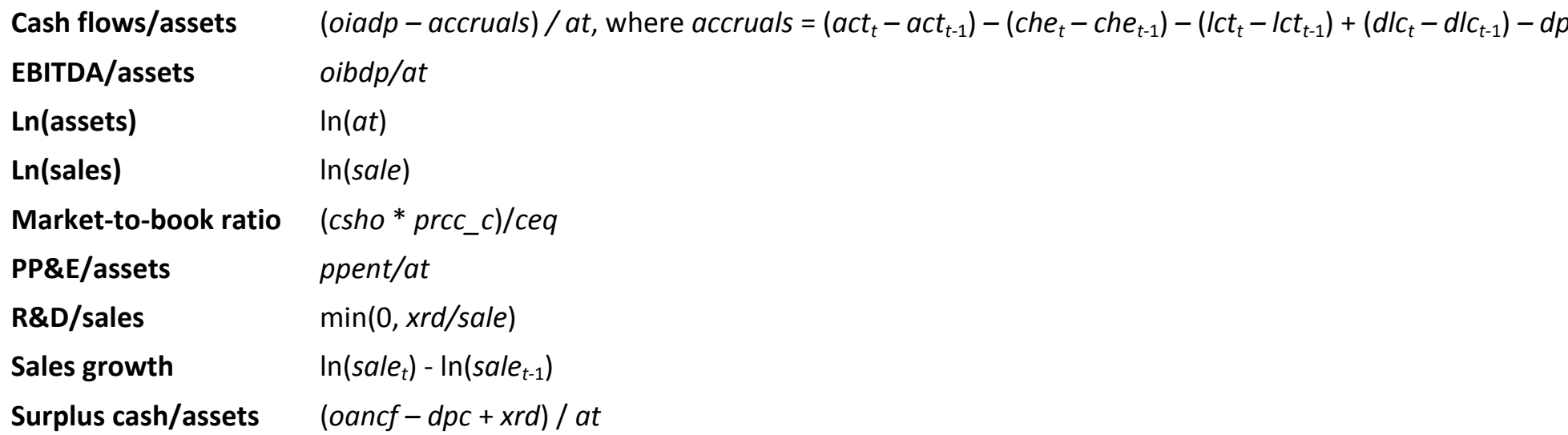

\section{Firm-level controls (from CRSP)}

Stock return

\section{CEO-level controls}

CEO age

CEO tenure

CEO exit

Ln(total pay)

Options/total pay

Salary + bonus
Calendar-year total stock return, compounded from monthly holding period returns where ordinary dividends are reinvested at month-end.

Age of CEO obtained from Disclosure database between 1990 and 2004, provided by James S. Linck.

Number of years a manager has been CEO, which is obtained from Disclosure database between 1990 and 2004, provided by James S. Linck. Missing values are imputed when possible.

Indicator that equals one in the year that a CEO turns over.

Calculated as $\ln (t d c 1)$ in the Execucomp sample and $\ln ($ salbon + othcomp + grantval) in the Yermack sample.

Calculated as option_awards_blk_value/tdc1 in the Execucomp sample and grantval / (salbon + othcomp + grantval) in the Yermack sample.

Calculated as salary + bonus in the Execucomp sample and salbon in the Yermack sample.

Note: All variables that represent a dollar value, including delta and vega, are adjusted for inflation using the annual average CPI index for urban consumers from the Bureau of Labor Statistics. 


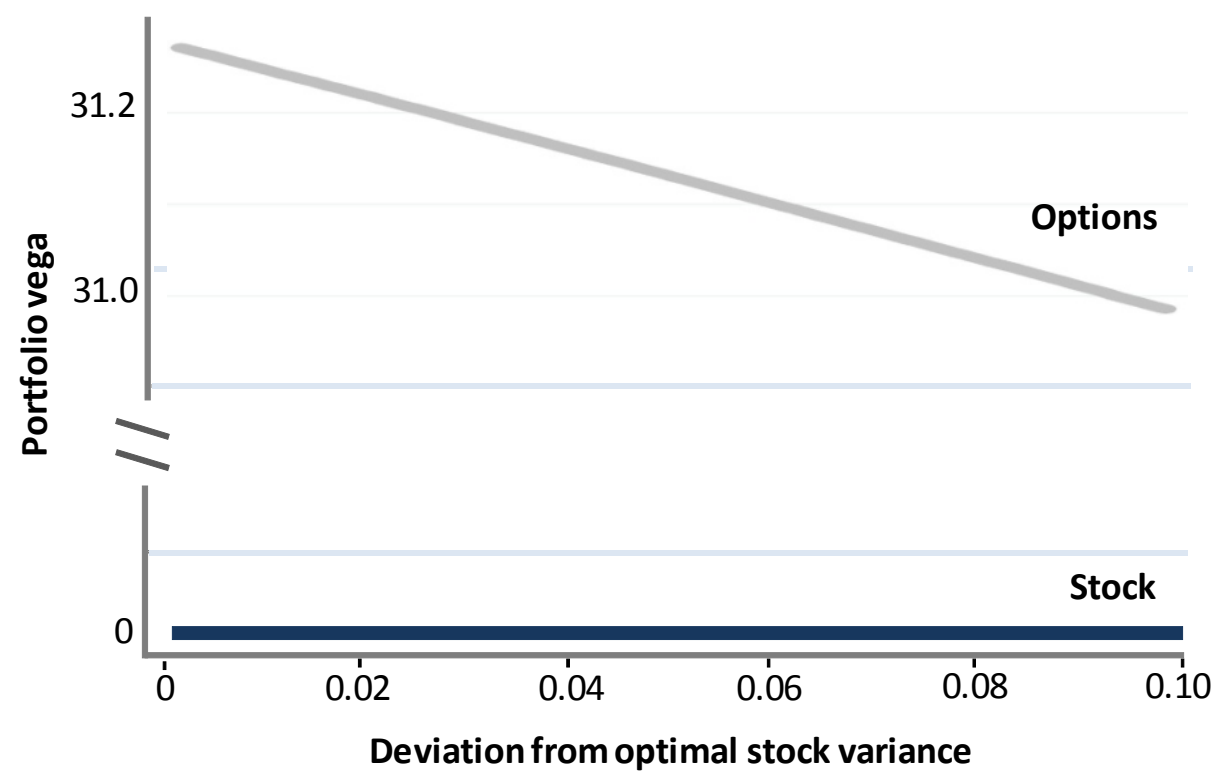

Fig. B.1. Portfolio vega after a mean-preserving increase in risk. This figure plots each portfolio's vega after a mean-preserving increase in stock variance. The portfolio vega is calculated assuming a zero dividend yield, a risk-free rate of five percent, and that the firm was at the manager's optimal level of stock volatility prior to risk increasing. 


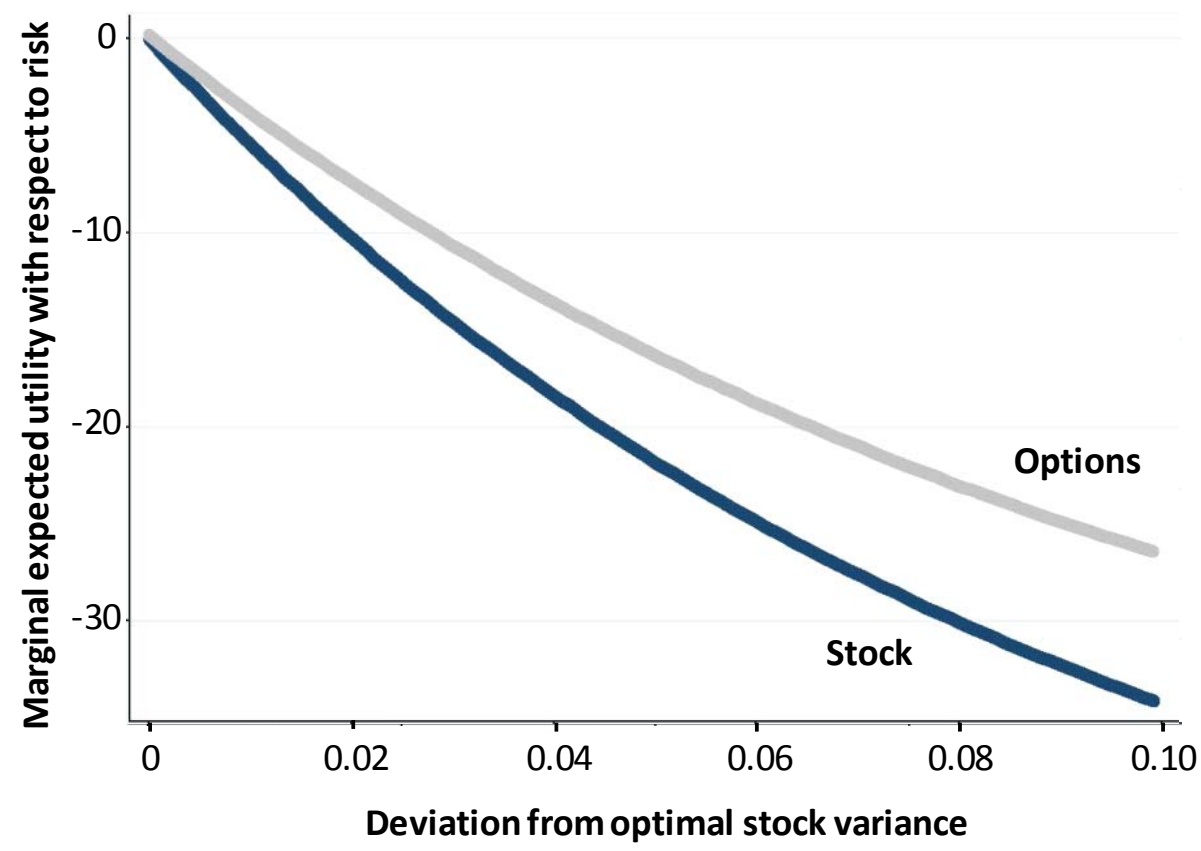

Fig. B.2. Marginal expected utility of risk after a mean-preserving increase in risk. This figure plots the manager's marginal utility of risk after a mean-preserving increase in stock variance. This is the numerical derivative of the manager's expected utility (shown in Figure 1) with respect to variance at points above the manager's previously optimal level of stock variance. 